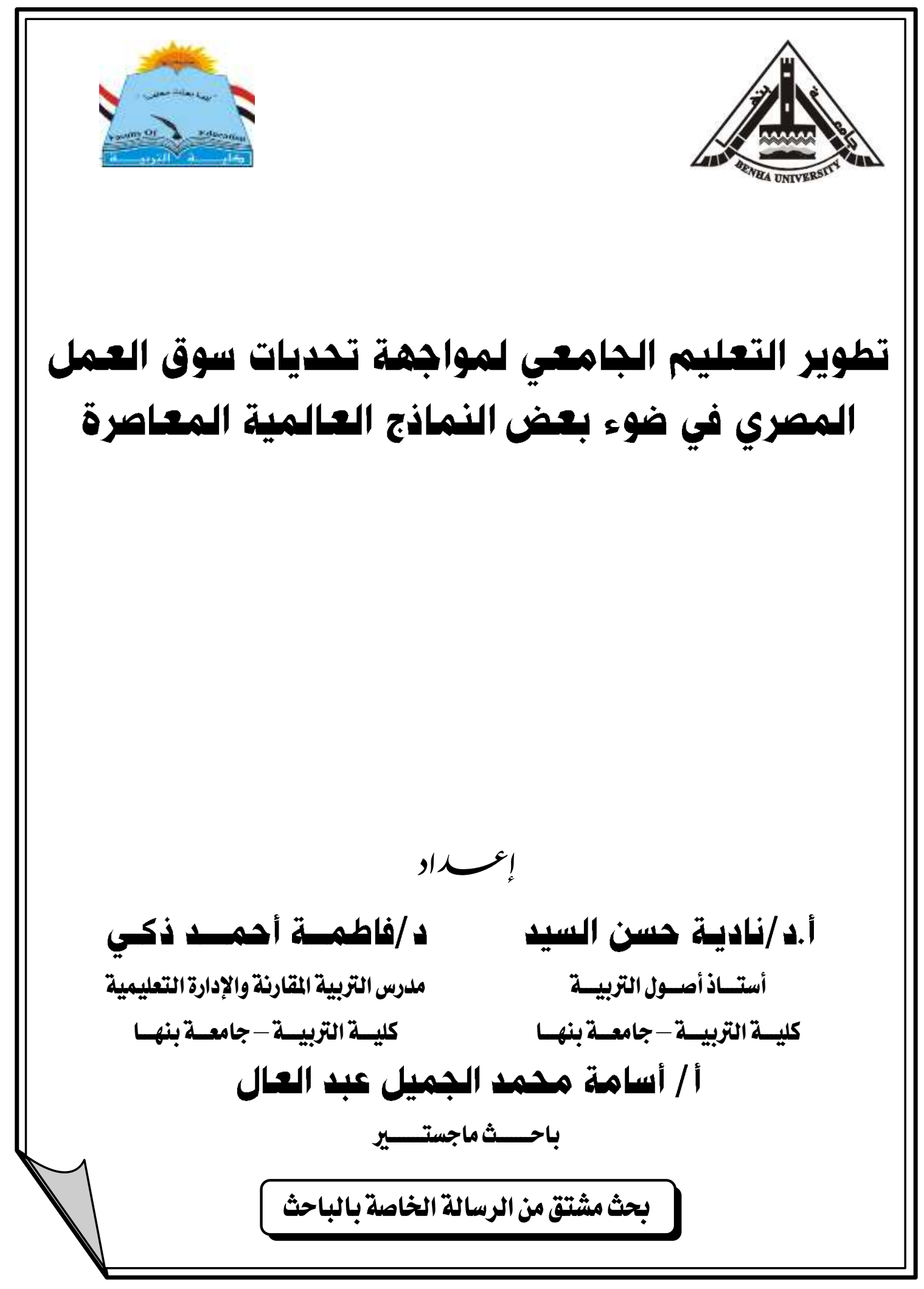




\section{تطوير التعليم الجامعي لمواجهة تديات سوق العمل المصري في ضوء بعض النماذج العالمية المعاصرة}

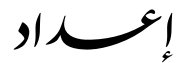

داطفمسة أحمسل ذكي

مدرس التربية المقارنة والإدارة التعليمية

كلية التربية - جامعة بنها
أ.دا/ناديسة حسن السيد

أستاذ أصول التربية

كلية التربية - جامعة بنها

\section{أ / أسامة محمد الجميل عبد العال}

باحث ماجستير

\section{ملذبــص البحــث}

هدف هذا البحث إلى تطوير التعليم الجامعي ليلبي احتياجات سوق العمل التي تتسم

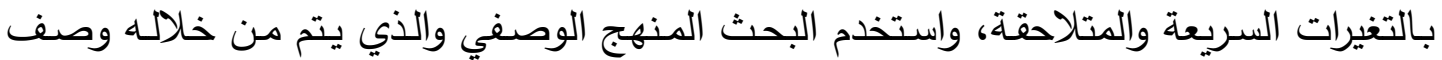

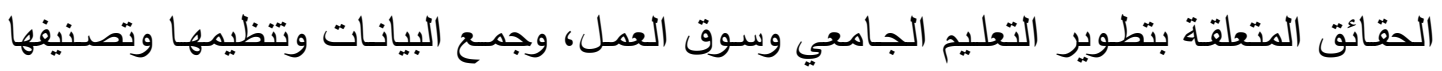
وتحليلها بدقة للوصول إلى وسيلة يمكن أن يتم من خلالها تطوير التعليم الجامعي، وارتكز

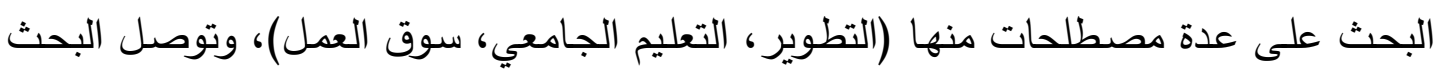

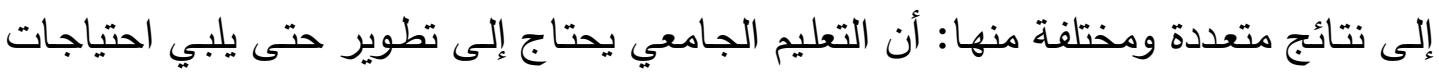

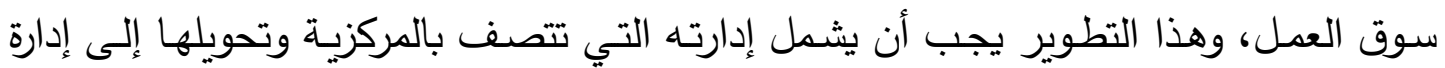

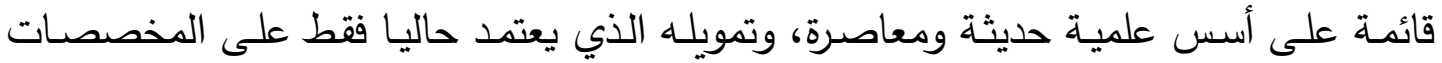

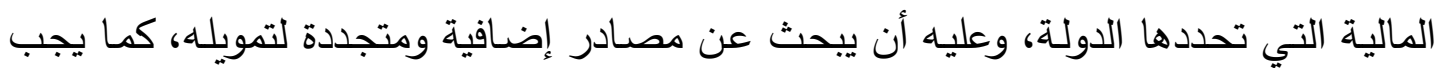
أن يشمل التطوير المناهج العقيمة وتطويرها لتناسب متطلبات سوق العمل الحالية والدستقبلية، وسياسة القبول التي تعتمد فقط على مجموع الطالب في الثانوية العامة وتحويلها إلى سياسة تراعي ميول وقدرات الطلاب واحتياجات سوق العمل. 


\section{مقدمهـة}

إن العالم اليوم يشهـ تطورات وتغيرات مستمرة في كل الميادين ومـع هذه التطورات

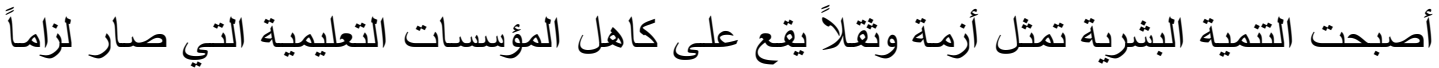
عليها أن تطور من أدائها وأن تحسن من كفاياتها للإسهام بشكل فاعل في بناء الإنسان وإعداده ليتعامل مع المتغيرات والتحديات التي لا تسكن أبداً. وفي الوقت الراهن تواجه مؤسسات التعليم الجامعي المصرية كثير من التحديات التئي التي

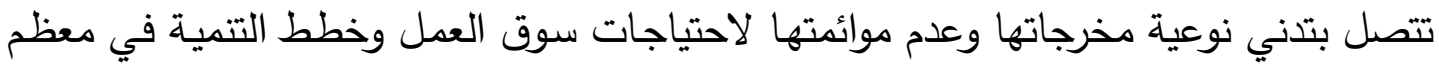

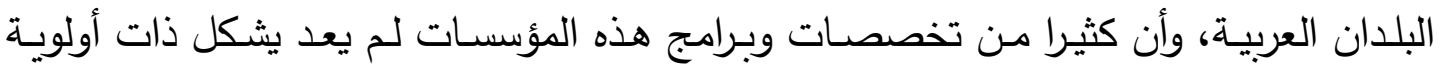

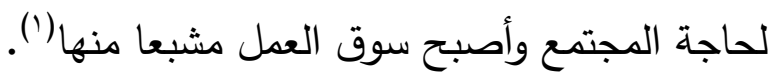
لذلك أصبحت قضية تطوير التعليم الجامعي وتحسين مستواه ورفع كفايته والتحكم في كلفته وحسن استثماره، من القضايا الرئيسة المثارة في الوقت الحاضر استجابة لتحديات العصر

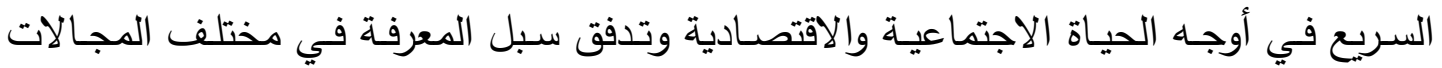
كنتيجة للتقدم العلمي وتطبيقاته التكنولوجية وقضية تطوير التعليم الجامعي ليست قضية كم بقدر ما هي قضية جوهر التعليم ومضمونه ومحتواه وطرائقه وكفايته (؟). والبحث الحالي يسعى إلى تطوير التعليم الجامعي المصري حتى يتمكن من تلبيـة احتياجات سوق العمل الحالي والمستقبلي في ضوء بعض النماذج العالمية المعاصرة.

يعاني التعليم الجامعي من العديد من الششكلات التي تعيق تطوره وهي المشكلات المرتبطة بتلبية احتياجات سوق العمل، ونظرا للتطورات والتغيرات المتلاحقة في كافة جوانب

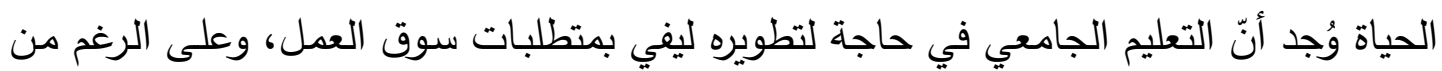

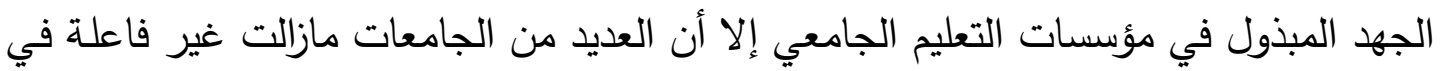
عملية تلبية احتياجات سوق العمل، وذلك بسبب القصور في بعض الجوانب بهذا النوع من التعليم، ويمكن صياغة مشكلة البحث في سؤال رئيس هو : س: ما جوانب تطوير التعليم الجامعي التي من خلالها يمكن تلبيـة احتياجات سوق العمل

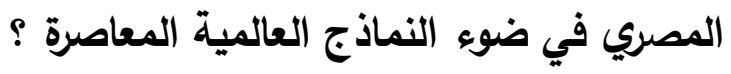


للبحث الحالي هدف رئيس وهو تطوير التعليم الجامعي حتى يتمكن من تلبية احتياجات سوق العمل الحالية والمستقبلية في ضوء بعض النماذج العالمية المعاصرة .

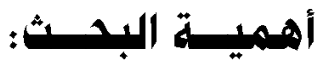

يمكن عرض أهمية البحث الحالي في عدة نقاط وهي كما يلي :

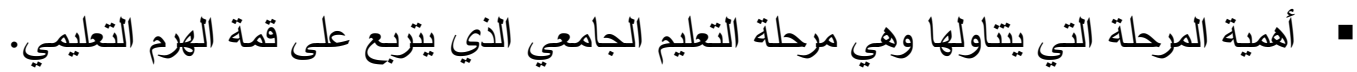

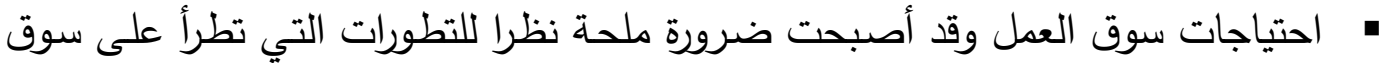
العمل بصفة مستمرة حسب ظروف العصر الذي نعيش فيه الآن.

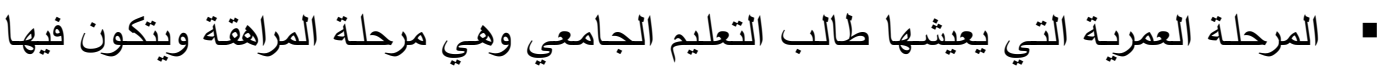

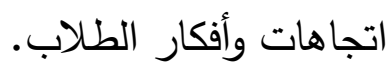
• حتمية التطوير للتعليم الجامعي في ضواء النماذج العالمية المعاصرة . منهــة البدـث: يستخدم البحث الحالي المنهج الوصفي لأنها يهتم بجمع البيانات والمعلومات الخاصـة

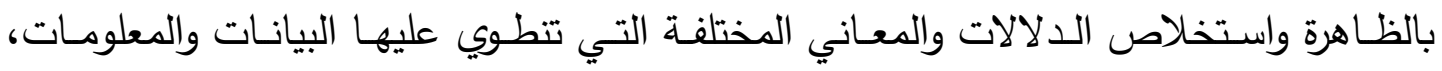
وإعطاء ذلك التفسير العلمي(") كما أنه يساعد على معرفة الوضع الراهن لبعض التهاني نواحي التصور بالتعليم الجامعي التي تحتاج إلى تطوير .

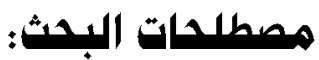
اعتمد البحث الحالي على بعض المصطلحات وهي :

The Development : التطوير يعني ذلك التغيير الكيفي والكمي في أحد أو بعض أو جميع مكونات النظام التعليمي

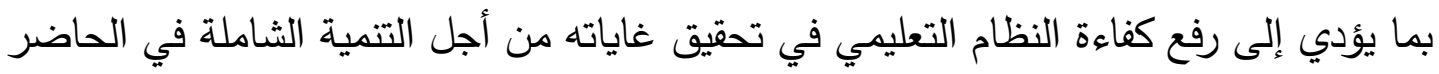

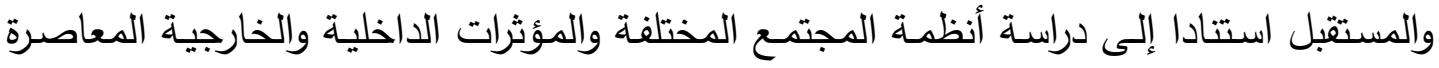
والمستقبلية ذات العلاقة بهام(ه).

The Higher Education : التعليم الجامعي كل أنماط التعليم الذي يتم في معاهد تخصصية (أكاديمي، مهني، تكنولوجي، وإعداد

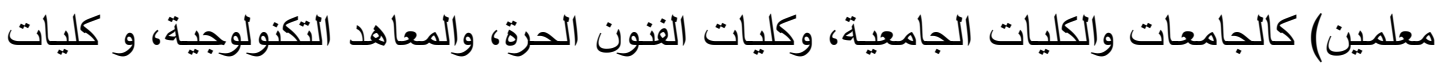


المعلمين، والثرط الأساسي للقبول هو الانتهاء من المرحلة الثانويـة والتي تقبل عامة طلابا متوسط أعمارهم حول الثامنة عشر (i). ويعرف إجرائياً بأنه: هو تعليم يتم في مؤسسات جامعية يلي المرحلة الثانويـة وهو أرقى الثى أنواع التعليم والطريق الوحيد للدراسات العليا.

\section{Labor Market : ب-سوق العمل}

يعرف على أنه : المكان الذي يجتمع فيه كل من المشترين والبائعين لخدمات العمل

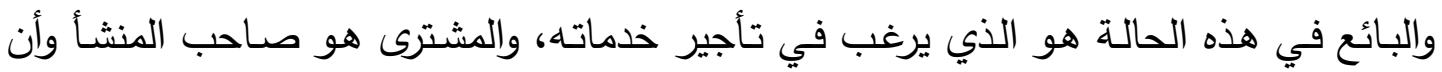

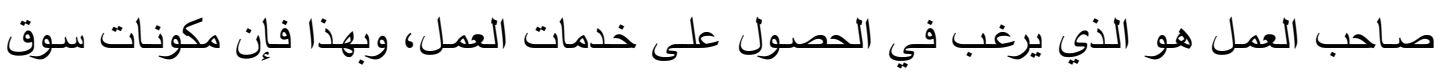

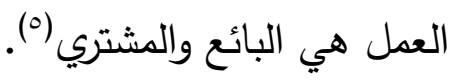
ويعرف إجرائياً بأنه: هو مكان افتراضي ينظم العرض والطلب للوظائف والحرف بما يتناسب مع مستوى وتخصص الخريج، وبما لا يتعارض مع ظروف المجتمع وسياسته العامة. الدراسات السابقة: يتم عرض الدراسات السابقة من الأقدم إلى الأحدث:

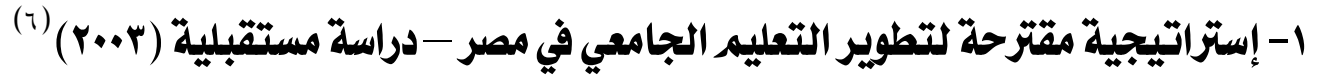

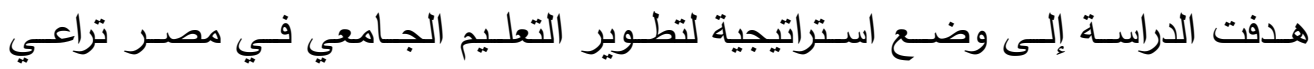

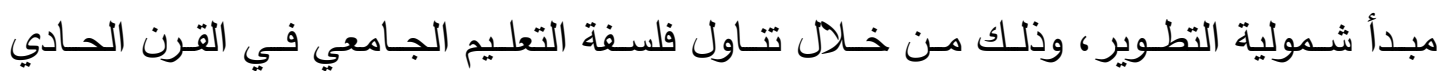

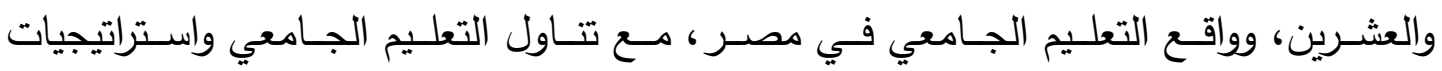

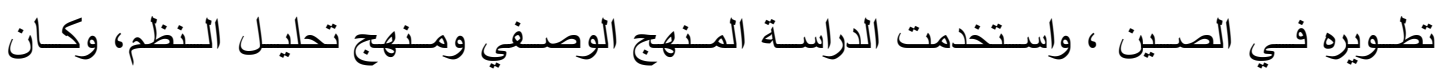

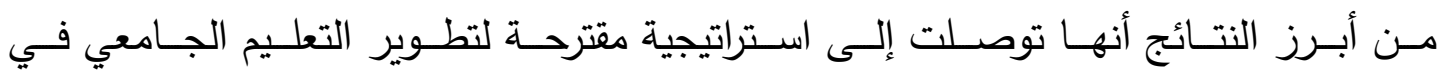

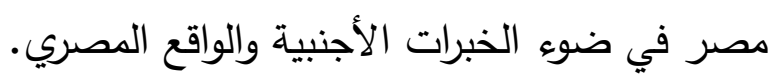

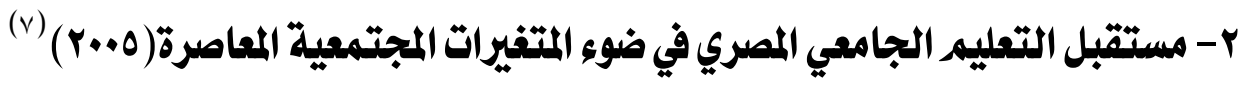

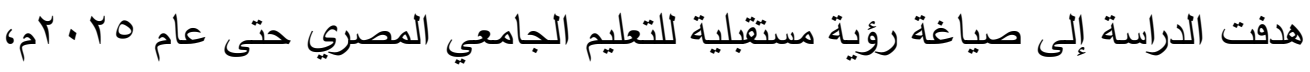

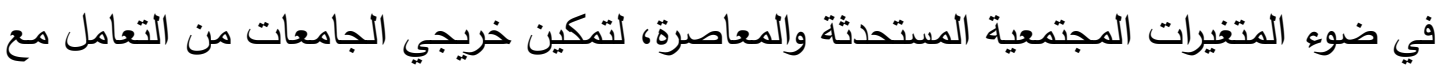

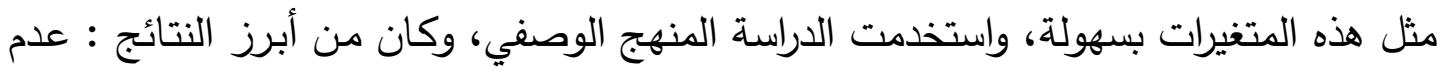

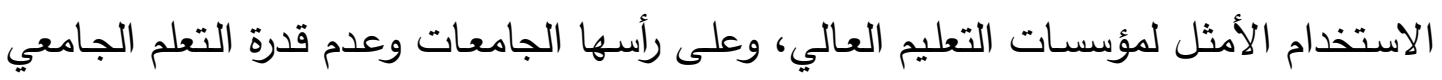


على مسـايرة التحديات العالميـة المعاصـرة وقصـور الجامعـة عن القيـام بواجبهـا تجـاه البيئـة المحيطة، والمساهمة في حل مشكلاتها نتيجة المركزية الخانقة.

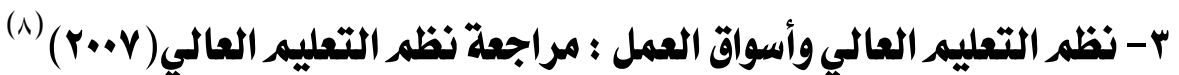

هدفت الدراسة إلى دراسة تأثير التوسع في مؤسسات التعليم العالي على أسواق العمل، وكيف يؤثر نلك على تحقيق أهداف النمو الاقتصادي والاجتماعي لهذه الدول، واستخدت الدراسة المنهج الوصفي، وكان من أبرز النتائج : أن هناك حاجة جيدة للاستمرار في التوسع على مستوى التعليم العالي، ويمكن تحقيق ذلك عن طريق توفير المزيد من الأماكن التعليم العالي.

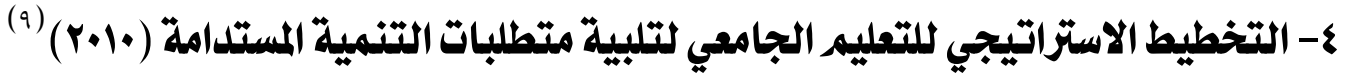
هدفت الدراسـة إلى وضـع خطة استراتيجية للتعليم الجامعي الحكومي المصري لتلبيـة احتياجات التتميـة المستدامة، واستخدت الدراسـة المنهج الوصفي في تلبيـة منطلبـات التتميـة المستدامة، واستخدمت كذلك منهج التحليل المستتبلي، وكان من أبرز النتائج : وضع خطة استراتيجية للتعليم الجامعي المصري لتلبية احتياجات التنمية المستدامة.

ه- دراسة العلاقة بـين أهميـة المعرفة باحتياجـات سوق العمل ومـدى جـودة مخرجـات الخدمات

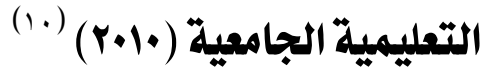

هدفت الدراسة إلى فحص تأثير المعرفة باحتياجات سوق العمل على تحسين أبعاد جودة الخدمات التعليمية، واستخدمت الدراسـة المنهج الوصفي، وكان من أبرز النتائج : أن سوق العمل الكويتي يعاني من ضسف مخرجات جامعة الكويت من عدة جوانب منها عدم المعرفة بمستويات اللغة الإنجليزية وعدم دعرفة استخدام الحاسب الآلي.

\section{Y- التعليه الجامعي المصري واقعه، ورؤية مستقبلية لتطويره (Y (Y) (1)}

هدفت الدراسـة إلى تحديد أبرز المشكلات التي تعـاني منها كفاءة التعليم الجـامعي

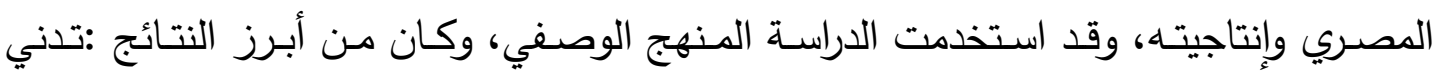
مستوى خريجي المرحلة الثانوية الذين يمثلون مدخلات التعليم الجامعي، تزايد أعداد الطلاب والتوسع في الكليات دون تخطيط مناسب. 


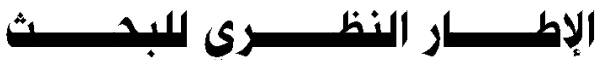

1-الوضع الراهن للتعليم الجامعي :

إنّ تلبيـة التعليم الجـامعي المصـري لمتطلبـات سـوق العهل لم تكن قضية مطروحـة

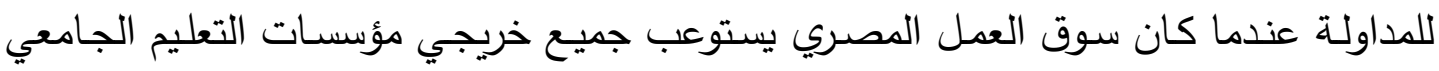
ويضمن لهم الوظيفة المناسبة إلا أن التغيرات والتحولات التي حدثت في السنوات الأخيرة في

المجالات الاقتصادية وسوق العمل المصري قد جعلت مثل هذا الربط قضية جوهرية(r'آ.

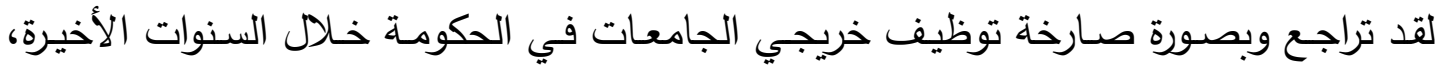

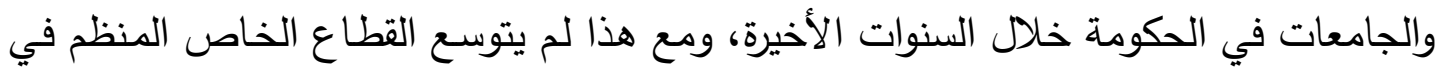
التوظيف بدرجة كافية، حتى يمكن احتواء العدد الكبير من المتعلمين الذين يدخلون سوق العمل

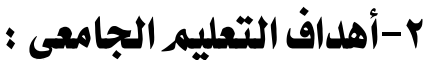

يمكن الاستتاد إلى دراسـات سـابقة للمجلس القومي للتعليم في رصد أهم الوظـائف

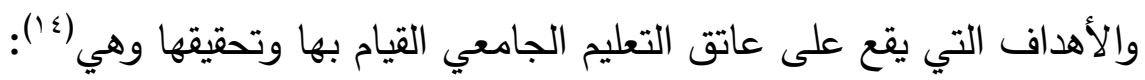
1- إعداد الأطر المتنوعة والمتطورة والقادرة من المتخصصين والقئي الفنيين والمفكرين للقيام

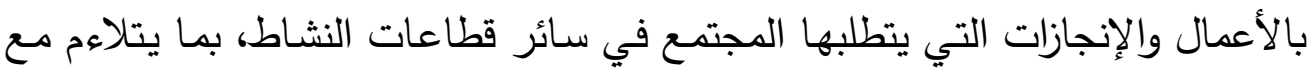
التطور الحديث والتحولات الاجتماعية والاقتصادية والسياسية الدحيطة بالبلاد، ويتوافق

$$
\text { مع أهداف وبرامج وتطلعات التنمية الثاملة. }
$$

r- القيام بالدراسات العليا في مختلف المستويات، في نطاق الإستراتيجية الوطنية والتعليمية

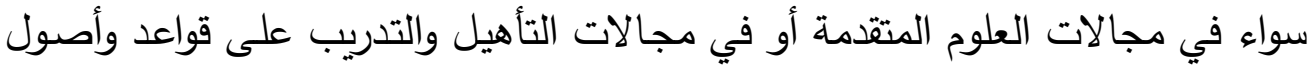

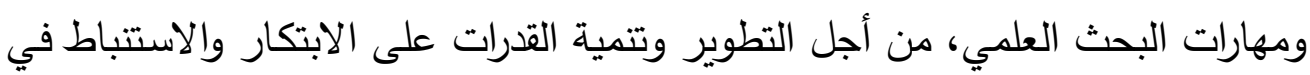
مختلف مواقع العمل ومراكز التنمية والتطوير بها.

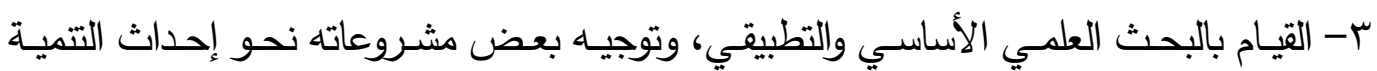
الاجتماعية والاقتصادية في المجتمع، إلى جانب الإنهام في تقدم العلوم والفنون والآداب.

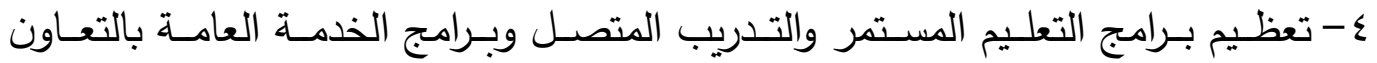

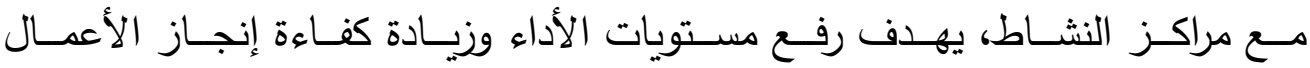
وعـلاوة على ذلك فإن مـن أهم أهداف التعليم الجـامعي التي ننشــها في عصدرنا 
الحاضـر ، تتميـة قدرات الطـلاب المعرفيـة والاجتماعيـة وصـقلها وإثرائهـا ومســاعدة

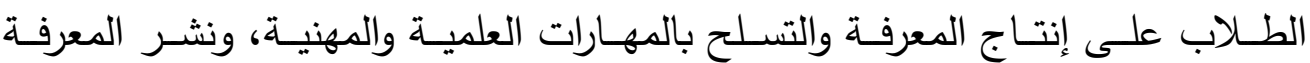
العلمية والسعي نحو تقدمهاب(10).

\section{ب-جوانب التطوير اللازمة للتعليم الجامعي لتلبية احتياجات سوق العمل في مصر :}

إن التعليم الجامعي المصري في حاجة ماسة لتطوير بعض مكوناته ليتمكن من تلبية احتياجات سوق العمل ويمكن حصر هذه المكونات فيما يلي :

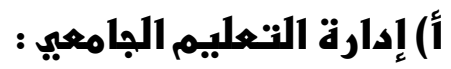

نظم قانون الجامعات إدارة التعليم الجامعي وجاءت في ثلاث مستويات فقد نص القانون

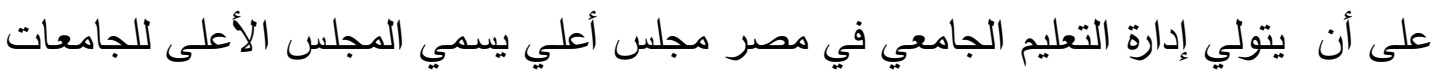

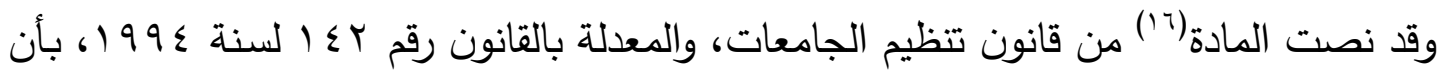

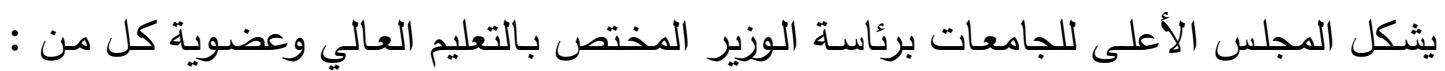

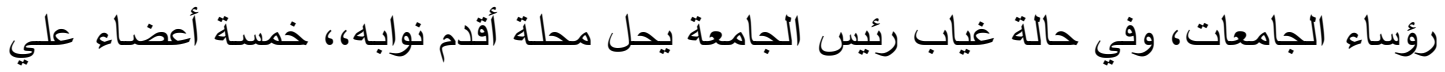
الأكثر من ذوي الخبرة في شئون التعليم الجامعي، والثئون العامة، يعينون لمدة عامين قابلة

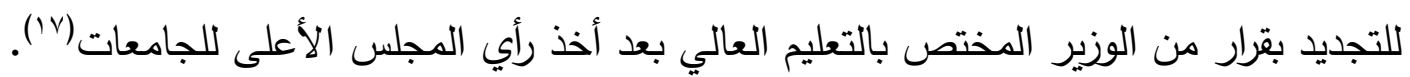

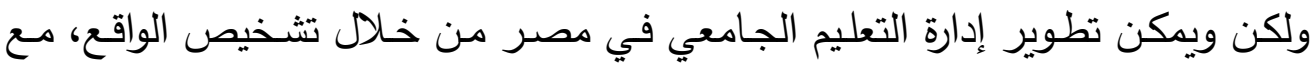

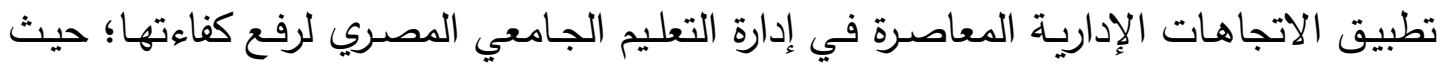

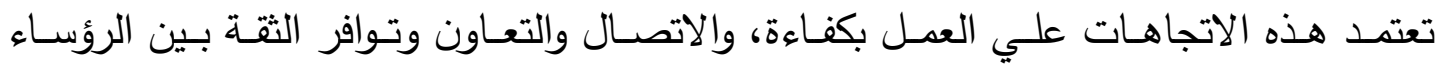

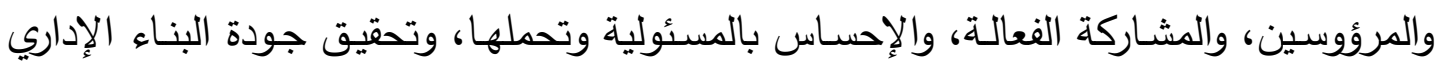

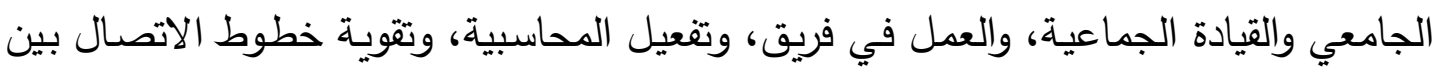

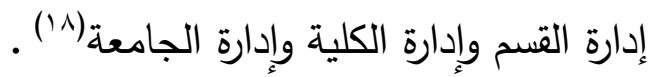

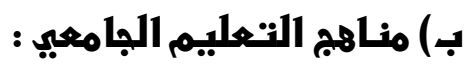

إن الواقع الملموس يعكس إهمال التعليم الجامعي للتطورات الجديدة في المناهج وعدم

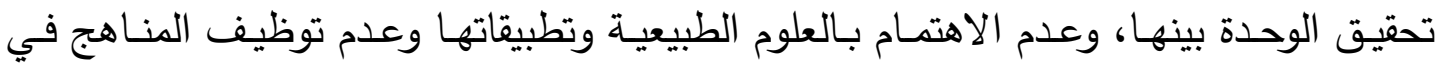

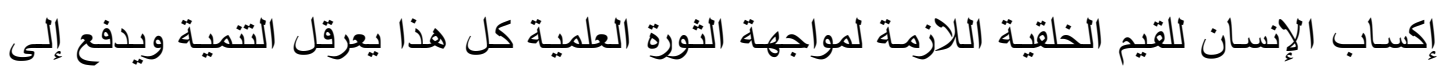

مزيد من التخلف والقلق (19). 
كما يجب على التعليم الجامعي أن يطور من مناهجه حتى يكون الخريج على قدر مناسب مما يتطلبه سوق العمل الحالي والمستقبلي حتى يتمكن من الالتحاق بسوق العمل، ولا شـك أن هنـالك علاقـة وثيقـة بـين مسـتوى الــخل والقدرة على اسـتخدام تطبيقـات تكنولوجيـا المعلومات، فالدول المتقدمة التي تضم (0 (\%) من سكان العالم يصل متوسط الفرد منها (Yo) ألف دولار سنوياً، بينما الدول النامية التي تضم نحو (^^\%) من سكان العالم لا يزيد متوسط دخل الفرد فيها على (ألف دولار ) فمن الواضـح أنه توجد فجوة رهيبة بين دخول الدول الغنية والدول الفقيرة(·r)، وقد يرجع ذلك إلى مدى امتلاك الأفراد لمهارات الالتحاق بسوق العمل.

\section{هـ) تمويل التعليم الجامعي في مصر :}

التعليم الجامعي كغيره من أنواع التعليم هو نشاط يحتاج إلى مخصصـات مالية حتى يتمكن من تتفيذ برامجـه ونشـاطاته ويعرف تمويـل التعليم الجـامعي بأنـه مفهوم يـرتبط لتحديـ مصـادر التمويـل بمختلف أنواعهـا حكوميـة كانـت أو غيـر حكوميـة، والعمـل على تتميتهـا واستثمارها، وتوجيهها على النحو الأمثل الذي يمكن المؤسسـات التعليميـة العاليـة من القيـام بأدوارها تجاه الفرد والمجتمع، وتحقيق أعلى استثمار بأقل تكلفة('). كذلك يعد تمويل التعليم الجامعي ضرورة سياسية من حيث اهتمام الدولة بمجانية التعليم الجامعي، وإقرارها لمبدأ تكافؤ الفرص التعليمية، وتؤكد على ذلك إحدى الدراسات والتي توصلت إلى عدم صحة الفرض القائل بأن مجانية التعليم الجامعي تأتي على رأس العوامل التي تؤثر في خفض كفاية النظام التعليمي، وأوصت بضرورة التزام الدولة بمجانية التعليم، والبحث عن مصادر تمويل أخرى لاعم التعليم في المجتمع(rr).

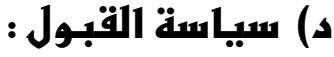

التعلـيم الجـامعي هـو نـوع مـن أنـواع التعليم وأرقـاه يلـي المرحلـة الثانويـة العامـة أو الفنيـة، و كـل مرحلـة أو نــوع أو مـن التعلـيم لـه سياسـة يتبعهـا فـي قبـول طلابــهـ الجـدد، وبصـفة عامـة فـإن سياسـة القبـول يقصــ بهـا الاختيـار والتوجيـه والتشـعيب وتقريـر نسـبـ التوزيـع لمختلـف قنـوات التعلـيم والتـدريب تبعَـا للفـروق الفرديـة بـين التلاميـذ مـن حيـث القـدرات والميـول والاهتمامـات ومقـدار النــو التحصـيلي فـي الاتجــاه المطلـوب ضــــانًا لكلاستخدام الأمثل للبشر وللممارسة الديمقراطية(r). 
ولكي يأتي التعليم الجامعي بثماره المرجوة لابد من تطوير سياسة القبول بهذا التعليم الراقي الذي يحتل قمة الهرم التعليمي في مصر ، فيجب أن يكون هناك علاقة قوية ودائمة بين متطلبات سوق العمل من حيث الكم والنوع وسياسة القبول بالتعليم الجامعي.

\section{ع- دور التعليم الجامعي في تلبيه احتياجات سوق العمل :}

يثهـ العالم المعاصر تغيرات جذرية في كافة مجالات الحياة، الأمر الذي يمكن معـه

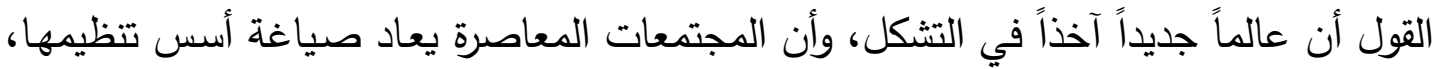

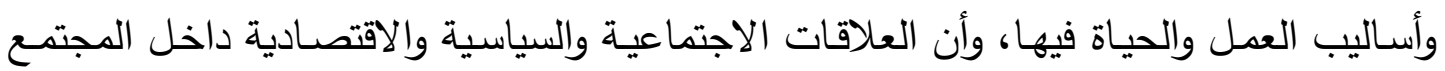
الواحد، بل وفيما بين المجتعات بعضها البعض آخذة هي الأخرى في التغيير.

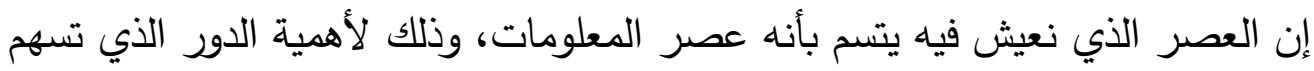

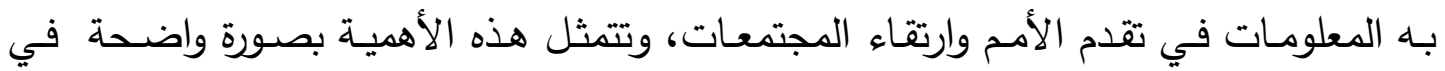

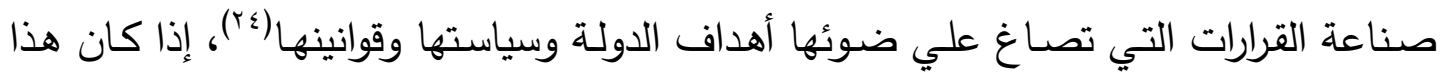

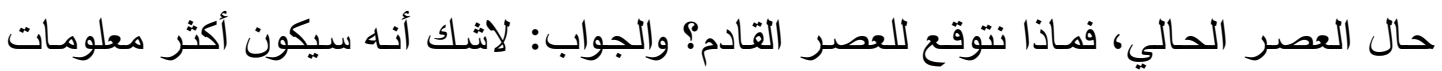

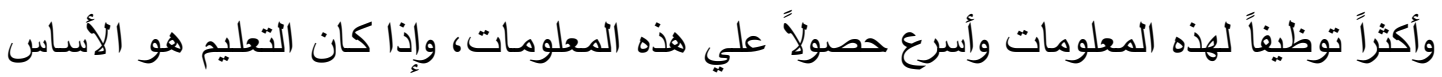

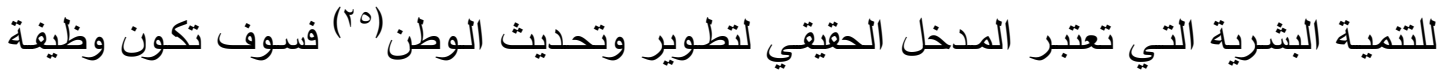

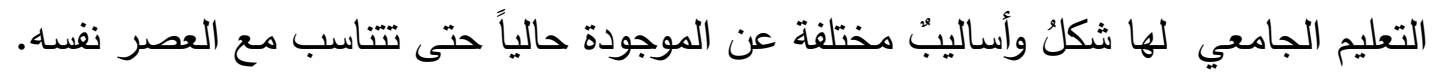

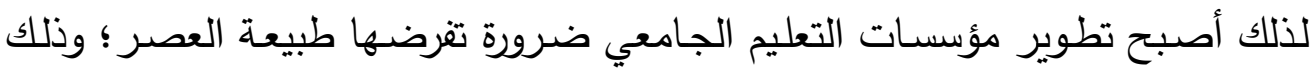
لمواكبة التطورات العالمية، والتكنولوجية، ومواجهة القضايا والمشكلات المختلفة. ونتيجة للتطور السريع الذي نحياه في هذا العصر (Tr(ب). وفي ظل الاقتصاد القائم على المعرفة سعت الجامعة إلى تطوير رأس المال البشري

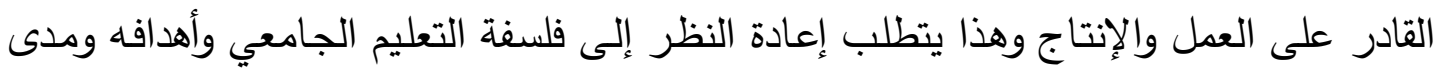
تكيفه مع البيئة الدولية، وتنامي الاستثمار في مجالات تجويد أداء الجامعات لتأثيرها الفعال في لألئي

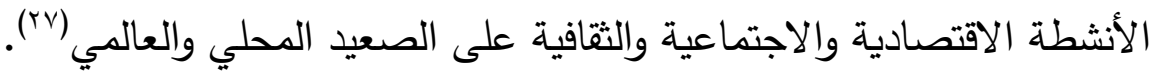

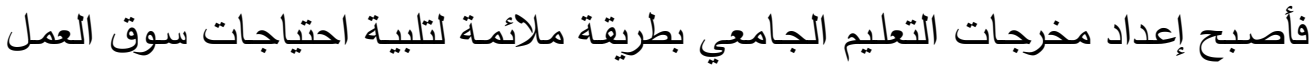

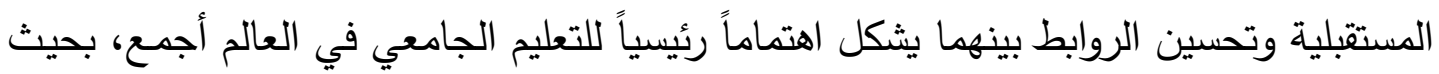

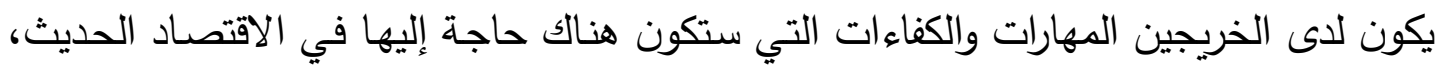
والمجتمع الحديث، وبذلك تتوافر فرص عمل لهم في هذه الأسواق (^^ان. 


\section{4-المشكلات التي تواجه التعليم الجامعي المصري في تلبية احتياجات سوق العمل :}

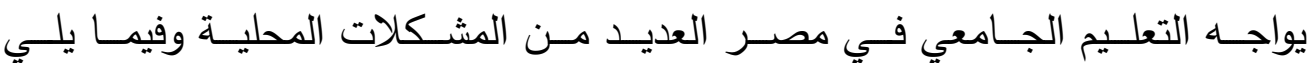

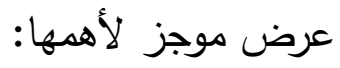

أ) الزيادة السكانية مع زيادة الطلب الاجتماعي على التعليم الجامعي ومن ثم الزيادة في الطاقة

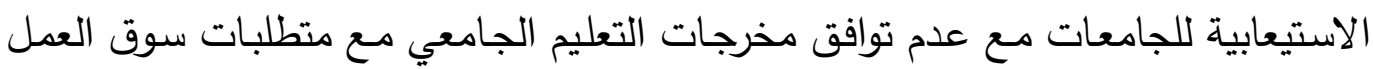

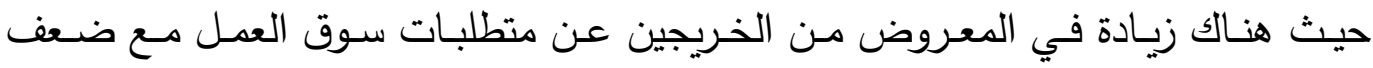

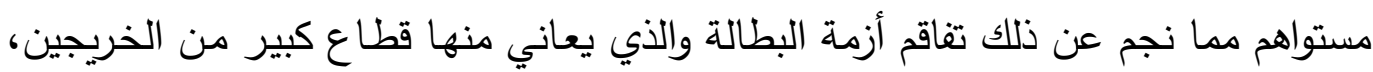

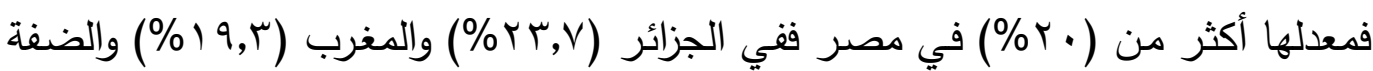

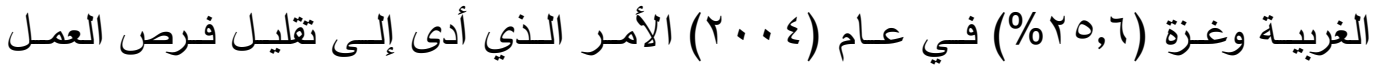

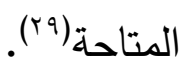

لذا تعد الزيادة السكانية من أخطر المشكلات التي تواجهاه مصر خلال القرن الحالي،

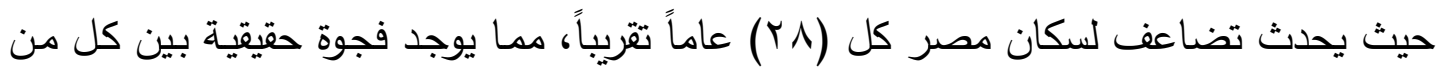
نمو السكان ونمو الموارد، هذا فضلاً عن أن سكان مصر عبر العصور يتركزون في مساحة

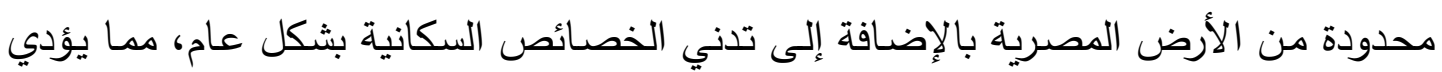

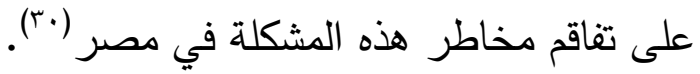
ب) عزلة الجامعات عن التفاعل الإيجابي لتلبية احتياجات سوق العمل المصري وحيث ينحصر دورها في إعداد سوق العمل بالخريجين من المؤهلين بالكفايات والمهارات اللازمة له من جهة ومن جهة أخرى يتم حرمان الطلاب من الخبرات العملية التي تعد أسـاس ممارسـة العمل الحقيقي، وكل ذلك نتيجة غياب الارتباط بين سياسات التعليم الجامعي والقوى العاملة

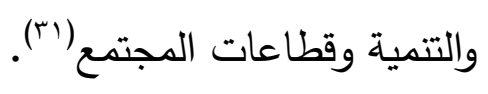

ج) يعد الطلاب من أهم مدخلات العملية التعليمية ويتعلق بهم العديد من المشكلات ومنها اعتبار المجموع النهائي في الثانوية العامة هو المعيار الوحيد للالتحاق بالكلية والتغاضي فئي

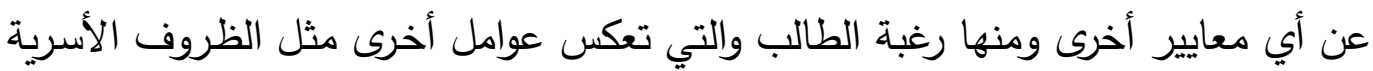
وجودة المدرسة والدروس الخصوصية، ومن ثم فلا تضع الطلاب في الأماكن المناسبة لهم كما تتجاهل قدراتهم الكامنة (rr). 
د) التتمية المهنية والعددية لأعضاء هيئة التدري، حيث يجاب أعضاء هيئة التدريس العديد

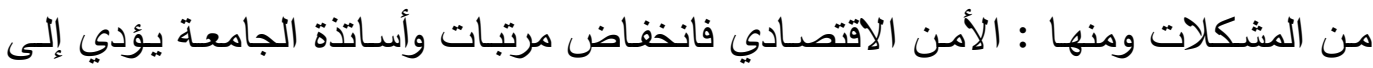

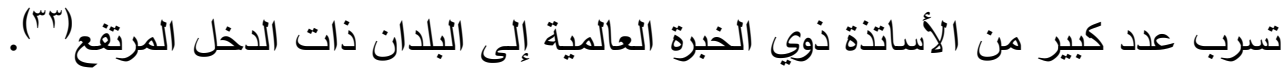

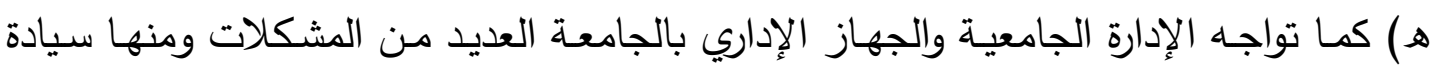
ثقافة الأفراد داخل المعاهد العليا والجامعات، وغياب ثقافة النظام عند تغيير القيادات سواء

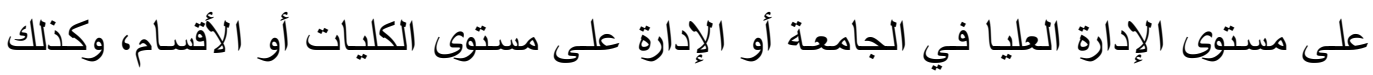
ضعف المستحدثات التكنولوجية في الإدارة الجامعية («ُمان.

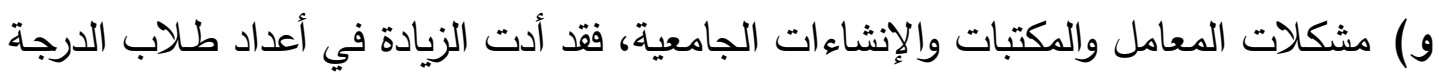

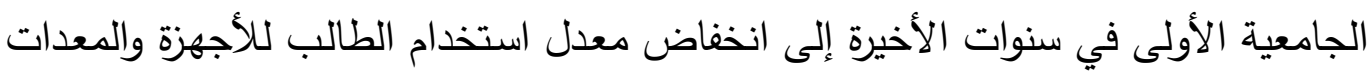

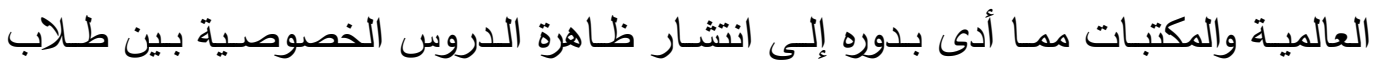

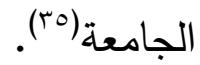

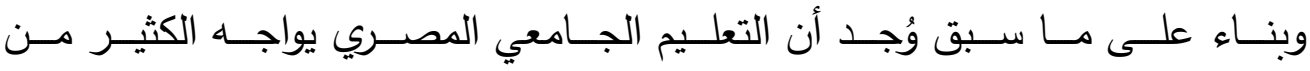

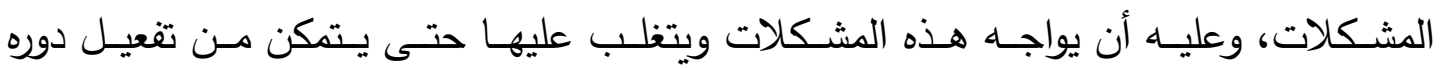
الهـام والفاعـل فـي تلبيــة احتياجـات سـوق العمـل المصـري مـن العمالــة المصـرية المـاهرة

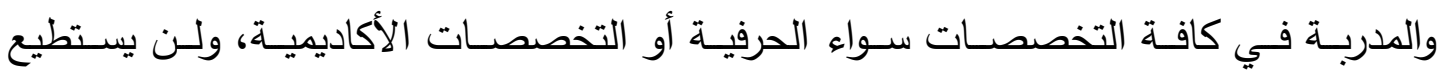

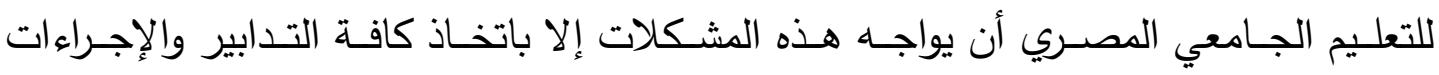
التي من شأنها الارتقاء بهذا التعليم مثل:

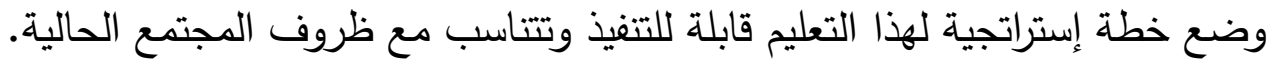
• الربط بين التعليم الجامعي ومتطلبات سوق العمل الحالية والمستقبلية.

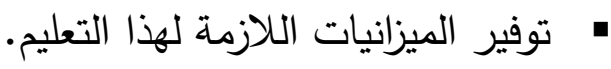
• تقيح مناهج التعليم الجامعي حتى تتناسب من التطورات الحالية من كافة النواحي.

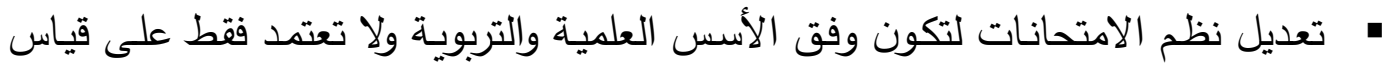
مستوى الحفظ واسترجاع المعلومات.

\section{V بعض النماذج العالية المعاصرة في تلبية التعليم الجامعي لاحتياجات سوق العمل :}

العلاقــة بـين التعليم الجـامعي وسـوق العهـل علاقــة مسـتمرة وتلقـى اهتمامـاً كبيـراً

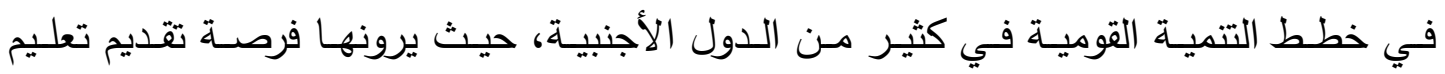


يعتمد على التدريب وتوظيف الموارد البشرية في خدمة المجتمع، لذلك تسارع الدول في تفعيل

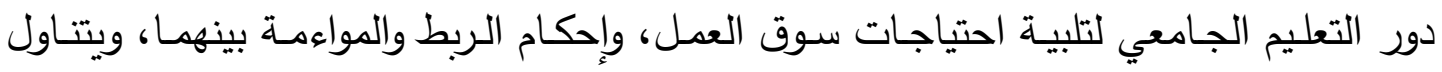
البحث الحالي في هذا الفصل عددا من النماذج العالمية في تفعيل دور التعليم الجامعي لتلبية التهاتية

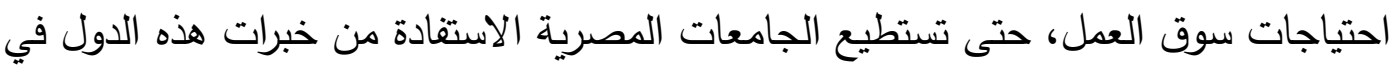

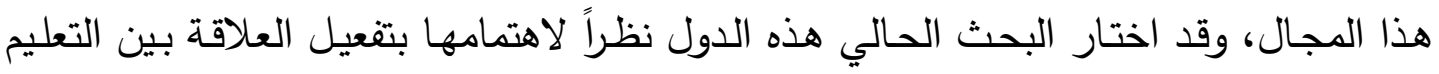

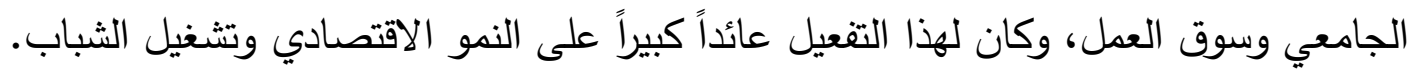

\section{أ) النـمـوذج الألمـاني فـي مجـال تفعيـل دور التعلبم البـامعي فـي تلبيـة احتياجـات}

\section{سووز العمل}

تعد ألمانيا من الدول المتقدمة التي تهتم بالتعليم وتربط بينه وبين سوق العمل في مجال

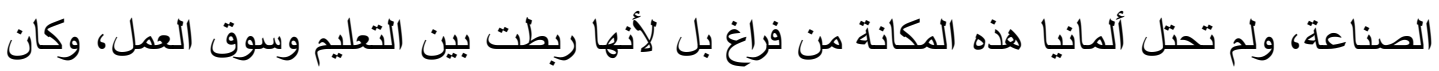

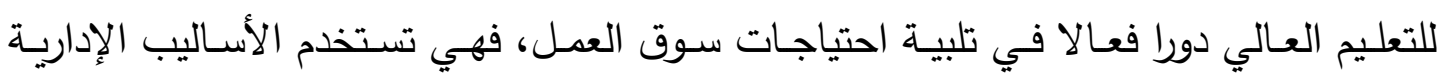

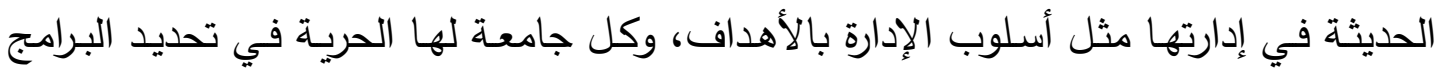

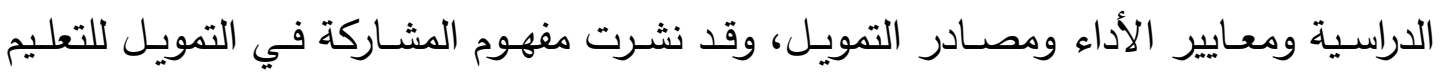

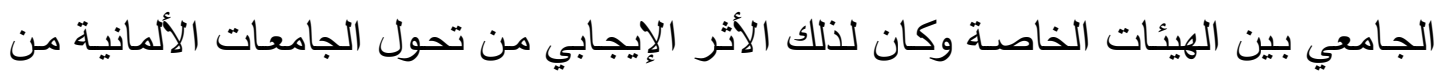

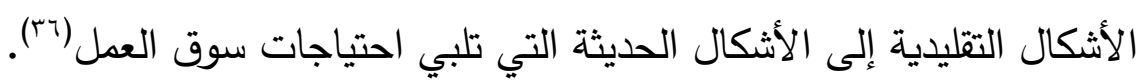

\section{1- نشأة وتطور التعليم الجامعي في ألمانيا:}

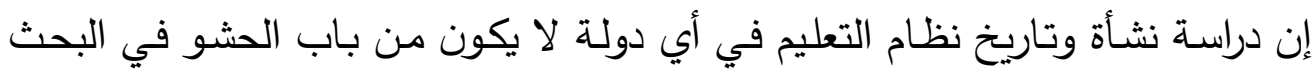

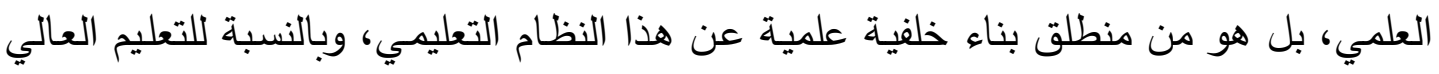

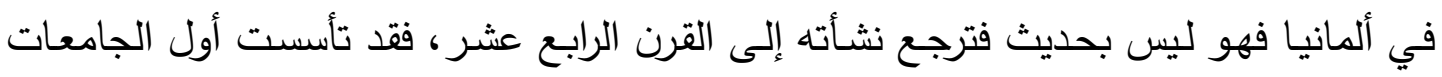

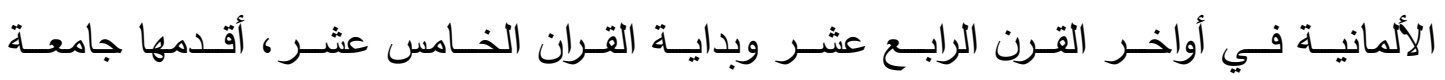

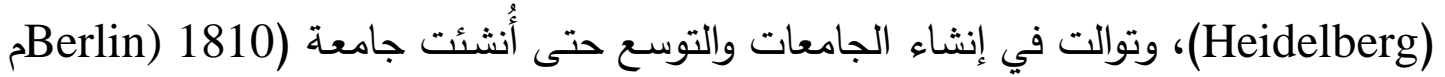

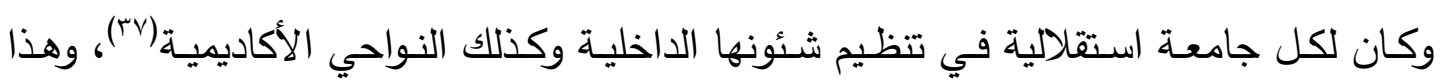
يعكس نظام إدارتها لا مركزيًا. والمتتبع لنظام التعليم الجامعي في ألمانيا يلاحظ أنه قد مر خلال تطوره بثلاث مراحل

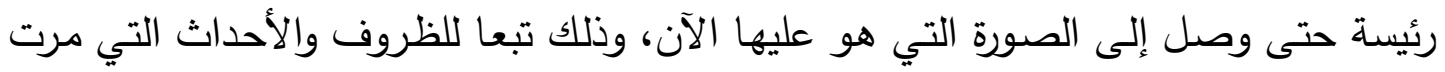
بها ألمانيا خلال فتراتها التاريخية المختلفة، تلك الظروف التاريخية التي تعد بمثابة خلفية محفزة ولانية 
أو مثبطة لتطور النظم التعليمية المختلفة، وفي ضوء الخلفية التاريخية للمجتمع الألماني يمكن تحديد المراحل التي مر بها نظام التعليم العالي في ألمانيا ثلاث مراجل الأولى كان فيها التعليم العالي موحدا، المرحلة الثانية انقسم فيها التعليم العالي إلى شطرين شرقي وغربي لكل منهها

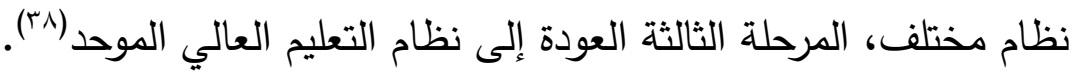

\section{ז-تفعيل دور التعليم الجامعي في تلبية احتياجات سوق العمل بألمانيا :}

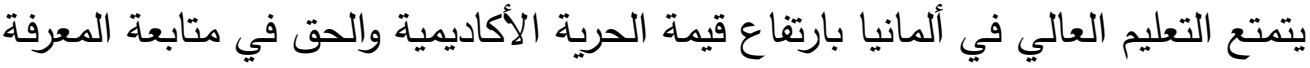

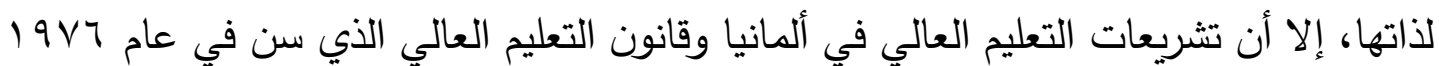

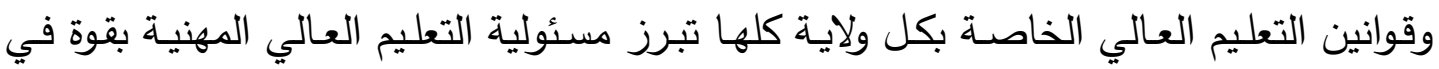

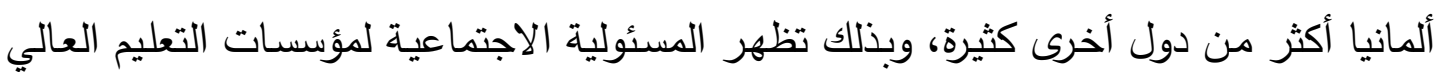

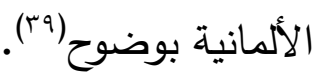

وهناك بعض المبادرات التي يشهدها التعليم العالي والتي اتخذت من أجل تسهيل انتقال الطلاب من التعليم العالي إلى الحياة المهنية العملية، ويمكن عرض ملامسح هذه المبادرة من لئن

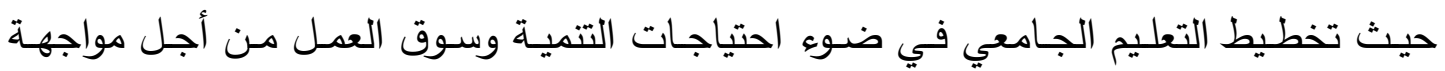

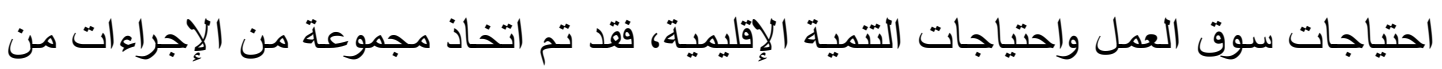

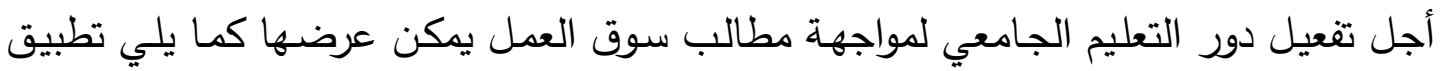

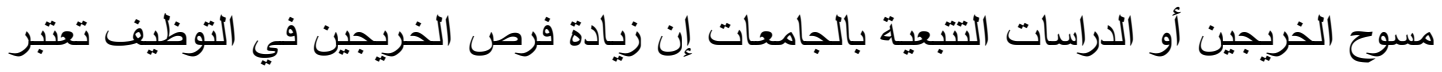

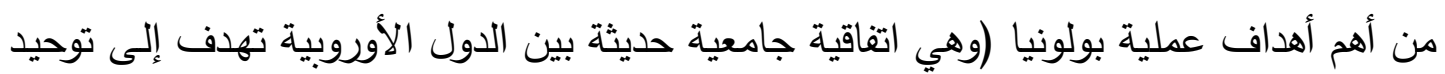

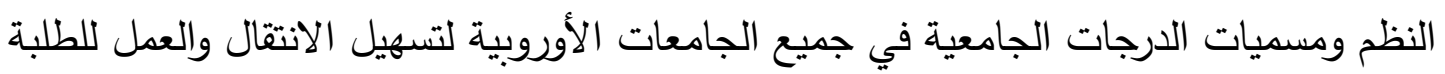

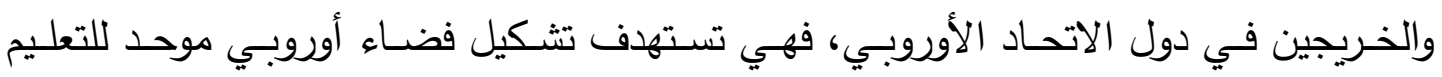
العالي (๕.)

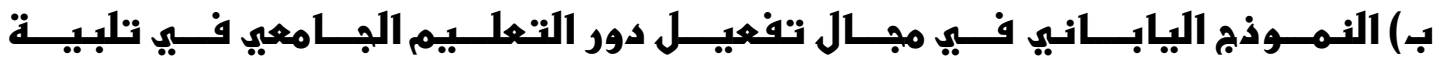 اهتياجات سوق العمل :}

تتناول هذه الخبرة تفعيل دور التعليم الجامعي في تلبية احتياجات سوق العمل باليابان

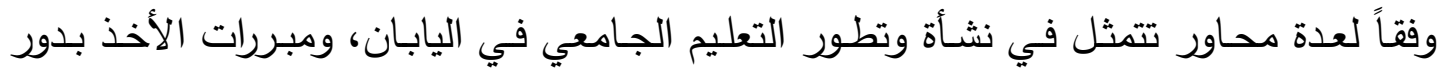
التعليم الجامعي في تلبية احتياجات سوق العمل باليابان، وتفعيل دور التعليم الجامعي في تلبية

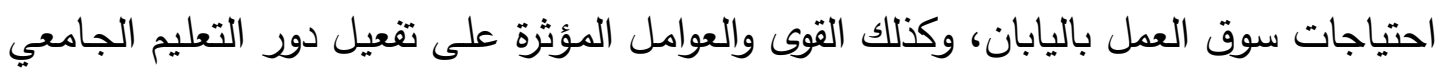


في تلبية احتياجات سوق العمل في اليابان والذي لها أثر على منظومة التعليم الجامعي أو تلبيتها لاحتياجات سوق العمل الياباني.

\section{ا-نشأة وتطور التعليم الجامعي في اليابان :}

يعتبر اليابانيون من الثعوب القديمة ذات الثقافة المميزة، وقد عاشوالئان طيلة ألفي عام

منعزلين في جزرهم، وفي القرن السادس الميلادي بدأ اتصالهم بالحضارة الصينية فأعجبوا بها لهابها

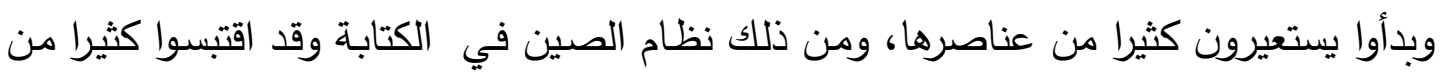

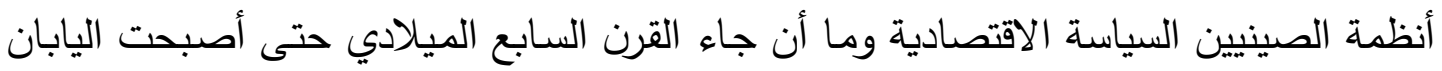
جزءا من حضارة الصين، واستمر نقلهم عن الصين وتقليدها حتى بدأت تظهر لهم ثقافة تميزهم وبهذا انتقلوا من مرحلة النقل إلى مرحلة الابتكار والتجديد (1).

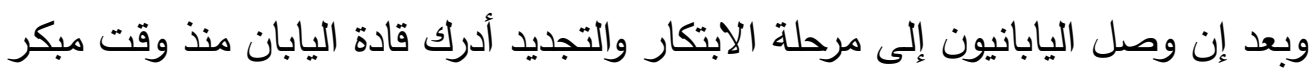

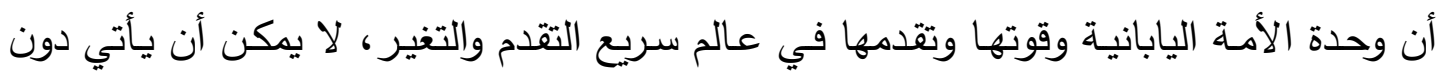

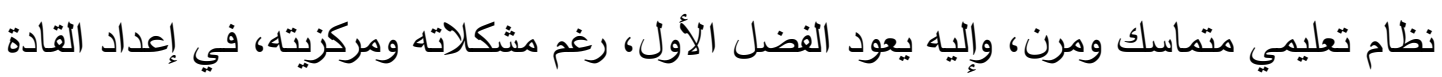

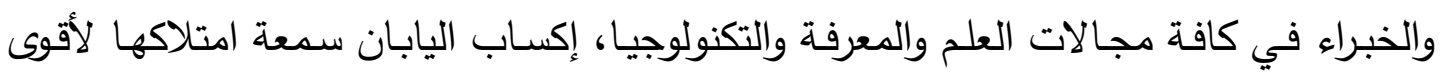

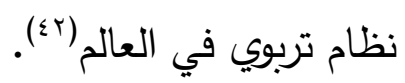
وفي الألفية الثالثة يوجد للى اليابان جامعة كبيرة للتربية تضم عددا من الكليات في

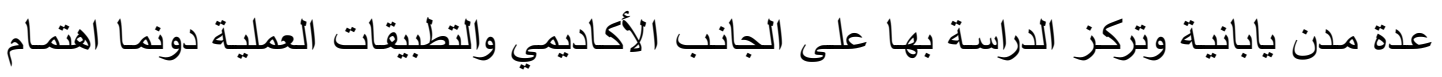

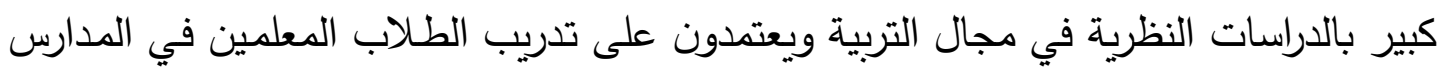

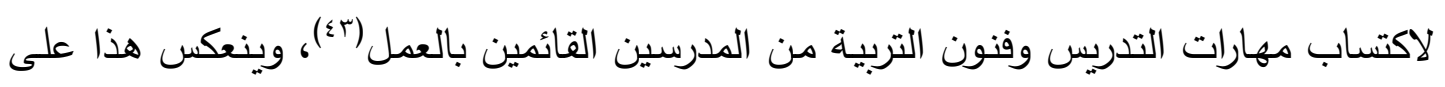
جودة خريج التعليم الجامعي الذي هو حجر الزاوية في سوق العمل المصري.

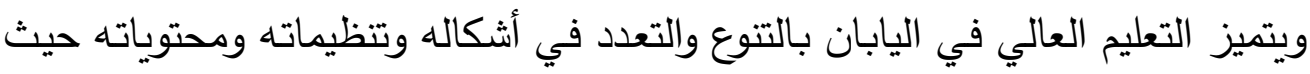

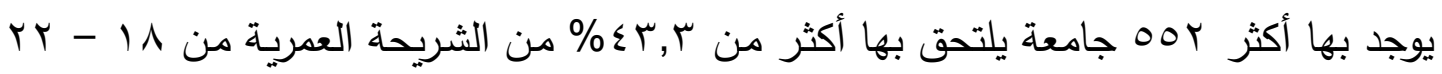

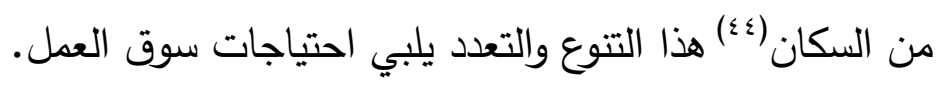

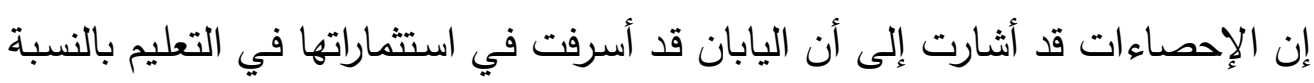

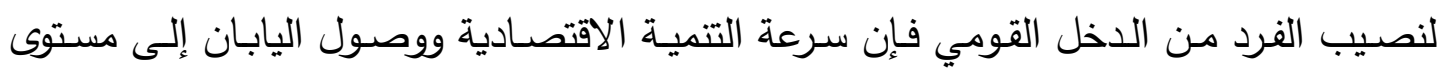

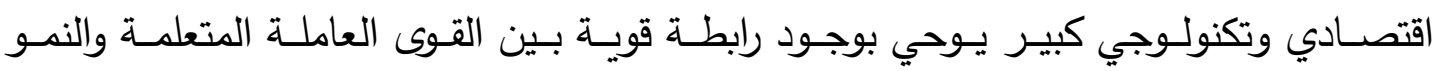
الاقتصادي هو ما بدأته اليابان حينما وضعت استثماراتها الضخمة في تتمية نظامها التعليمي لئي 


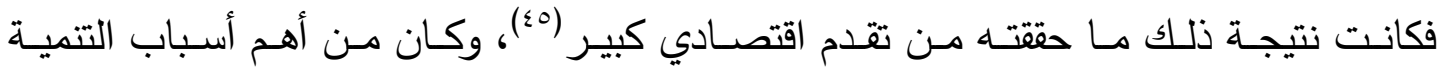
الاقتصادية والتكنولوجية نظامها المتميز في التعليم الجامعي.

\section{r-تفعيل دور التعليم الجامعي في تلبيتة احتياجات سوق العمل باليابان :}

يشهـه سوق العمل في اليابان تحديات كبرى داخليـة وخارجيـة وهذه التحديات نتيجـة

طبيعية للتطورات والتغيرات في كافة المجالات ومنها سوق العمل الذي يزداد الطلب عليه نتيجة

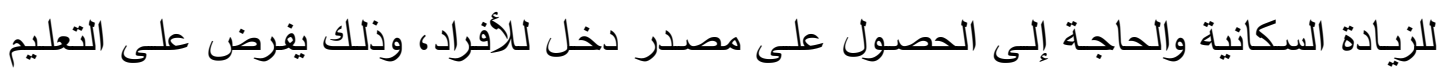

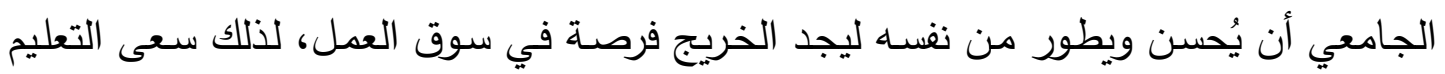

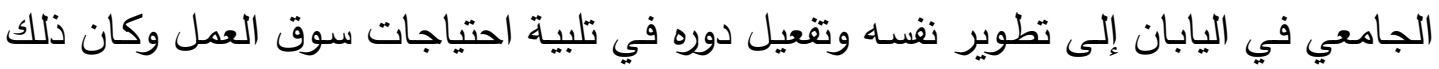

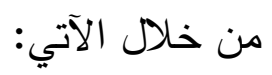

ت تقدير التعليم الجامعي الياباني بشكل ملحوظ مـن اليابانيين، كمـا تم احترام الحريـة

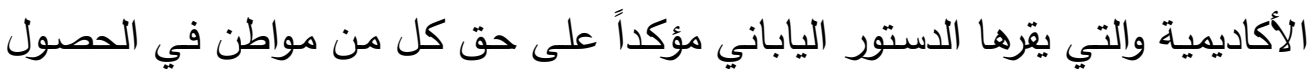

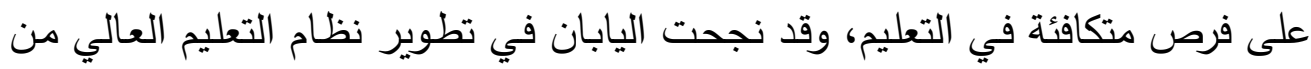

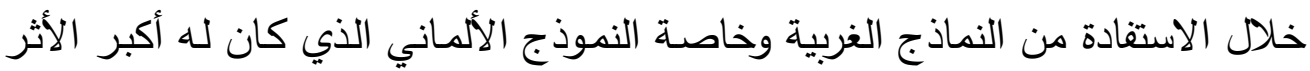

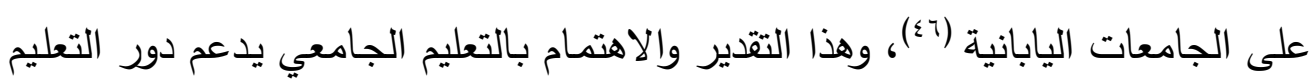
الجامعي في تلبية احتياجات سوق العمل. دعم الطلاب من كافة النواحي، ففي جامعة طوكيو يتم دعم الطلاب مهنياً، وذلك من سن الطيل

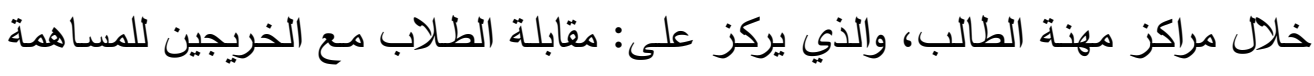

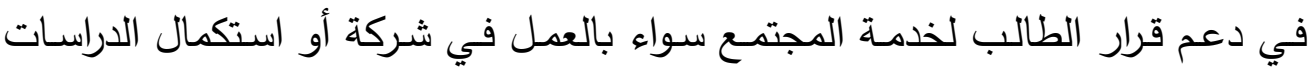

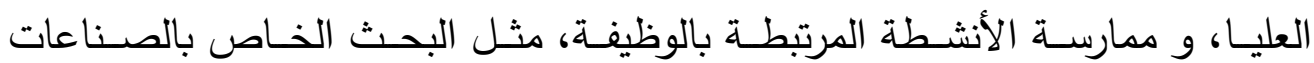

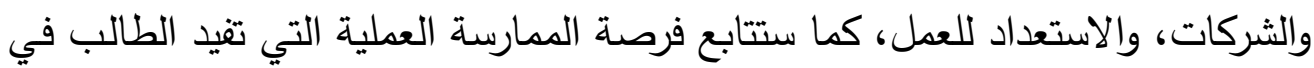

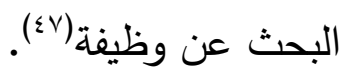
الارتباط الوثيق بين الجامعات ومراكز البحث والصنـاعة وإدارة الدولـة ذات العلاقة،

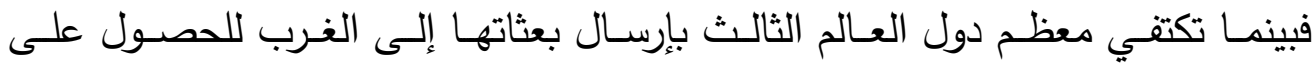
الدكتوراه، ومعتبرة ذلك نهاية المطاف، فإن البعثات اليابانية ممثلة في العلماء والباحثين والمهندسين لها زيارة كل عام إلى المصانع ومراكز البحث للتعرف على التطورات في لئان 
الأفكار والوسـائل العلميـة والتكنولوجية ومعاينـة النماذج الصناعية الجديدة، ودراسـة كل

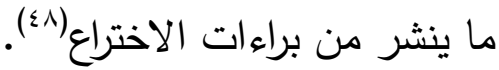

إيجاد آلية للربط بين التعليم الجامعي وسوق العمل في اليابان، فهناك ورش تدربيـة مهمـة في العمليـة التعليميـة للكليـات التكنولوجيـة، وتسـير المعجزة في أمساكن الـوش التدربيـة بالجامعـات يـتم اسـتئجار المؤسسـات الصـناعية والمراكز التدريبيـة، لأجـزاء التـدرببات الصــناعية المطـورة، بهـدف ربـط الدراســة النظريـة بتكنولوجيـا الصــاعة المطورة(§9).

\section{ج) النمــوذج الســـغافوري فـي مجــال تفغعيـل دور التعلــيم البـامعي فـي تلبيــة 1هتياجات سوق العمل:}

إن المتتبع لتاريخ سنغافورة يدرك أن سنغافورة كانت تحت الاحتلال حتى عام 1970 وأن شعبها مـن عدة أصـول (هنديـة - صـينية - مـلاوي)، وبعـد الاستقلال حققت سـنغافورة انجازات هائلة وانتقلت من كونها دولة من دول العالم الثالث إلى دولة من الدول المتقدمة خلال فترة قصيرة خمسون عاما، بذلك تكون سنغافورة ضربت مثلا رائعا في الإصرار وقوة الإرادة في تحقيق أهدافها.

ويعد المجتمع السنغافوري مجتمعًا متماسگًا ومتناسقًا وشامخًا في علاقاته وقيمه حيث

الدقـة المتتاهيـة والاحترام والانضـباط، حيـث يعتبر الفرد ترسًا في المجتمـع يتكامـل مـع بقيـة المنظومة، فكلها مسئولية مشتركة تقع على جميع أفراد المجتمع، فالبيئة النظيفة تدل على مدى الرقي الحضـاري، والخضـرة تكسـو كل شـهر مـن الأرض دلالـة على التفاؤل والأمـل والتطلع عـع بشغفٍ إلى المستقبل(·) وهذا التماسك والترابط كان سببا رئيسا في هذا التقدم الغير عادي. لذلك تعد سنغافورة تجربـة فريدة نموذجية لدولة صغيرة نامية استطاعت أن تتنقل إلى مصساف الدول المتقدمة التي حققت خلال خمسة وثلاثين عاماً إنجازات غير عادية وذلك بإتباع منهجية اقتصـادية محددة من خلال تصميم رجالها على الوصول إلى الأهداف المنشودة باقر الطرق

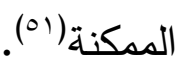

\section{ا- نشأة وتطور التعليم الجامعي في سنغافورة :}

سـنغافورة مـن الدول الحديثة على السـاحة الدوليـة، واهتمامها بـالتعليم العـالي مـرتبط بكيانها كدولـة مسـقتلة، فبعـد أن استقلت سـنغافورة في عـام 970 ومنـذ السبعينات أي بعد 
استقلال سنغافورة بفترة قصيرة وهي سعى جاهدة إلى تخطيط التعليم العالي في إطار سياسة

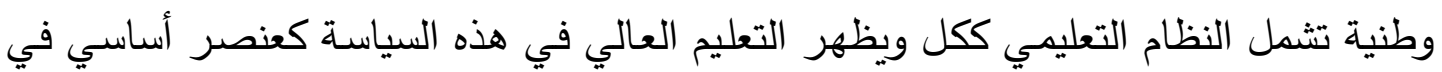

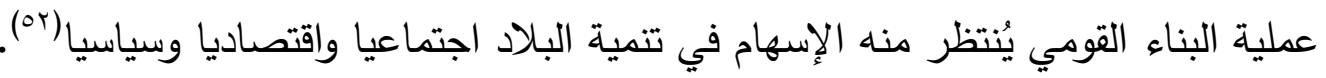

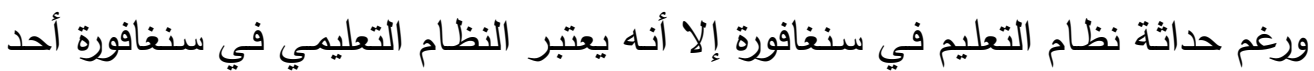

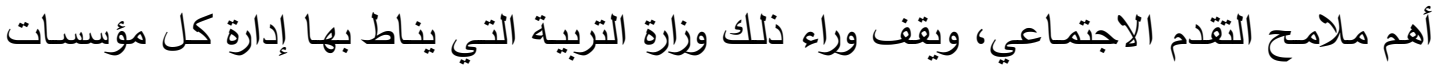

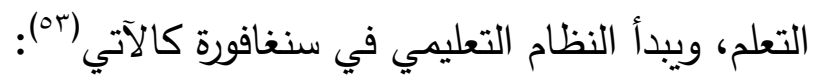

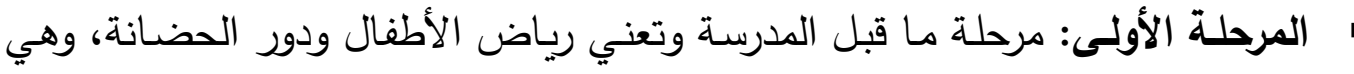

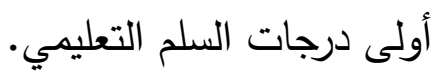
المرحلة الثانية: المرحلة الابتدائية وهي تمثل نواة التعليم النظامي وتمتد من 1 - 11 11 سنة. المرحلة الثالثة: مرحلة التعليم الثانوي وهي التي تلي المرحلة الابتدائية وتتفاوت مدة الدراسة بها ؟ - م سنوات. المرحلـة الرابعـة: المرحلة الجامعية، وتلـي المرحلـة الثانويـة، وتعتبر جامعـة سنغافورة الوطنية من أكثر الجامعات، وتضم ^ كليات بالإضافة إلى خمسين دائرة علمية تمنح

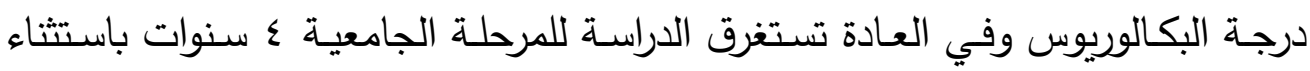
كلية الهندسة والطب تستغرق 0-7 سنوات.

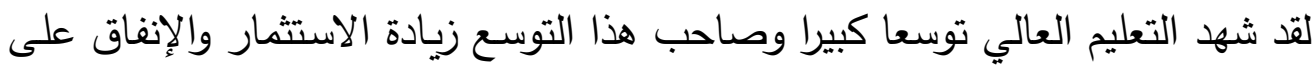

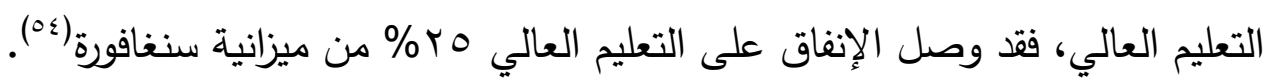
ז-تفعيل دور التعليم الجامعي في تلبيتة احتياجات سوق العمل في سنغافورة:

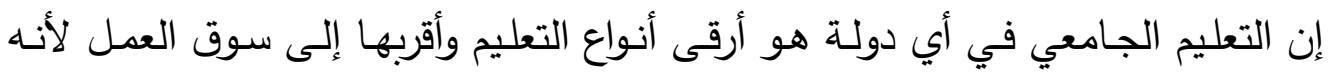

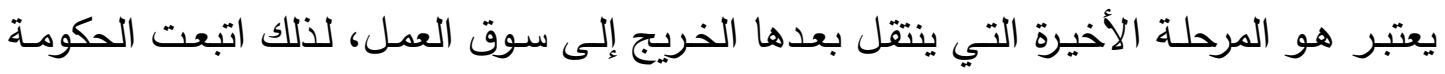

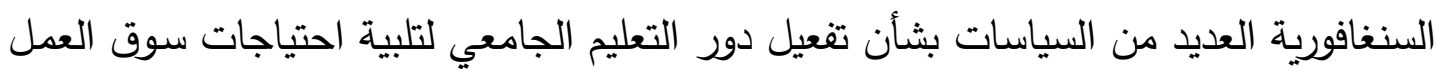
وتتمثل فيما يلي: • يتم التخطيط في النظام السنغافوري على المستوى الرسمي (الحكومي) من خلال عدد

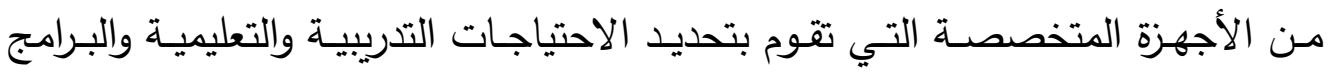
الملائكة لإثباع تلك الاحتياجات من وجهة نظر سوق العمل، كما تقوم هذه الأجهزة 
بصياغة أهداف محددة (Targets) في ما يتعلق بأعداد ومستويات الباحثين عن عمل والعاملين المراد تطويرهم (هo). وللتصدي لهذه المشكلات بدأت سنغافورة بتجربـة تطبيق المدارس الإككترونيـة حيث

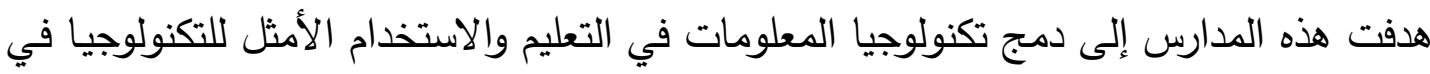

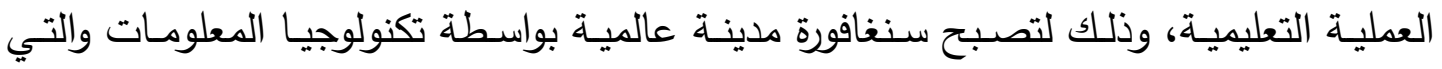

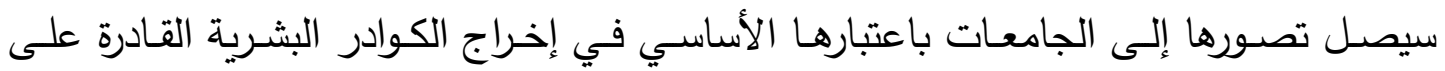

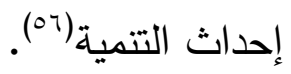

ومـن بين عناصـر الإستراتيجية الجديدة في سنغافورة إدخال بعض المقررات حول الاستثمار والمشروعات في مناهج التعليم الجامعي حيث يتسلح خريجو جامعة سنغافورة الوطنية

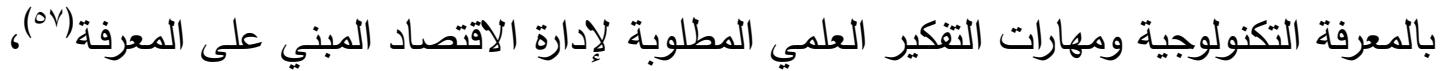

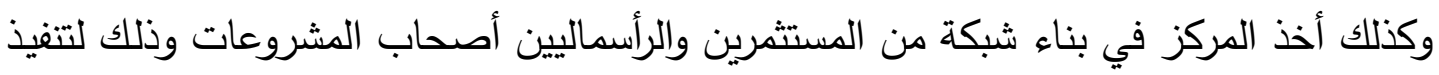
المشروعات والابتكارات المنبثقة عن الجامعة والحصول على الدعم اللازم لتلك المشروعات، وخاصة من خارج الجامعة(ه).

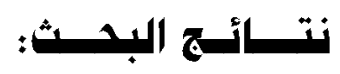

توصل البحث الحالي إلى العديد من النتائج منها ما يلي :

تفتتر إدارة التعليم الجامعي إلى الأساليب الإدارية الحديثة والمعاصرة.

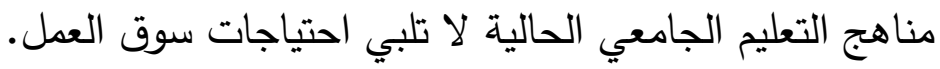

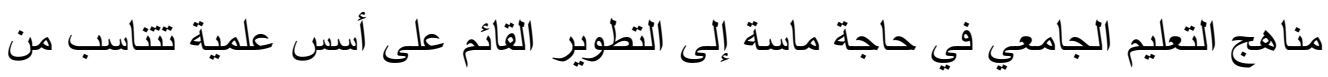
متطلبات احتياجات سوق العمل. تعجز مناهج التعليم الجامعي عن إشباع حاجات الطلاب والمجتمع. • يعتمد التعليم الجامعي على المخصصات المالية التي تحددها الدولة له من ميزانيتها السنوية. تعجز ميزانية التعليم الجامعي عن الوفاء بمتطلباته اللازمة لتنفيذ برامجه ونشاطاته التعليمية.

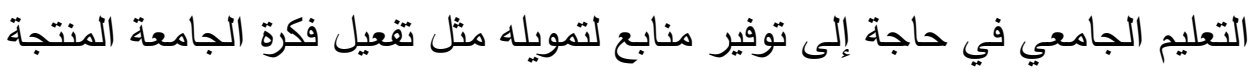
يتبع التعليم الجامعي سياسة قبول عقيمة تعتمد فقط على مجموع الطالب في الثانوية العامة.

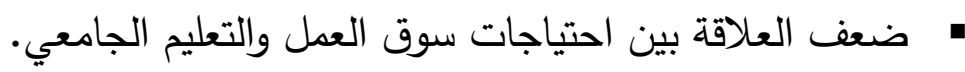
الافتقار إلى وجود قاعدة بيانات توضح الاحتياجات الفعلية لسوق العمل من حيث الكم والكيف 
التعليم الجامعي لا يراعي ميول وقدرات الطلاب في سياسة القبول. زيادة فرص الخريجين في التوظيف بألمانيا نتيجة عمل مسوح للخريجين بالجامعات.

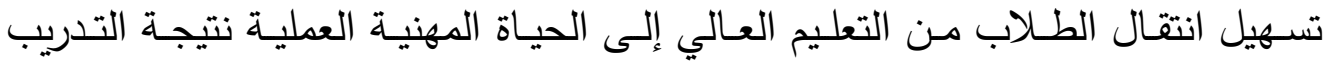

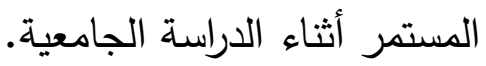
الارتباط الوثيق بين الجامعات اليابانيـة ومراكز البحث والصناعة وإدارة الدولـة وذلك الك

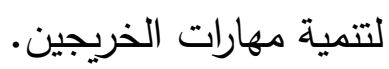
ه التتبؤ بجانب العرض والطلب في سوق العمل الياباني.

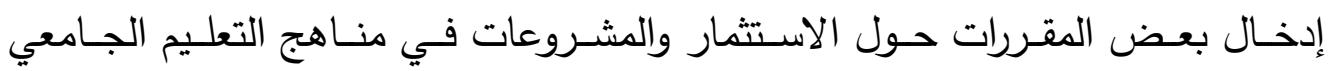
السنغافوري مما يعود بالنفع على الخريجين في ميدان العمل.

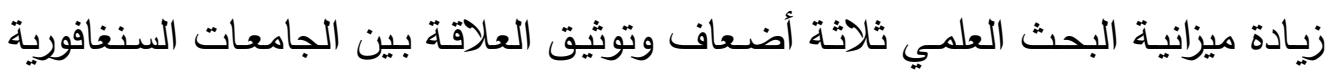

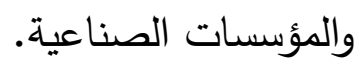

إعادة النظر في سياسات القبول بالتعليم الجامعي وأن يكون القبول في الجامعات على

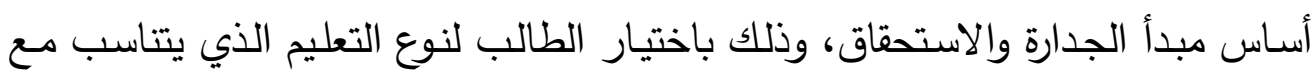

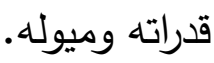
ضرورة عمل تنسيق بين مؤسسات العمل للخريجين ومؤسسات التعليم الجامعي لإحداث نوع من التتسيق والتنظيم والاطلاع على مستجدات وتطورات سوق العمل المتغيرة.

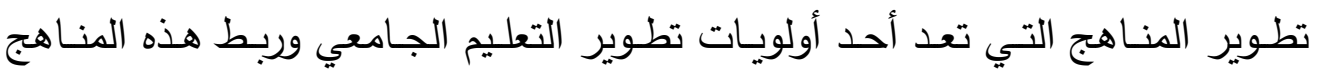
باحتياجات سوق العمل وذلك لمواجهة المشكلات والتحديات العنصرية.

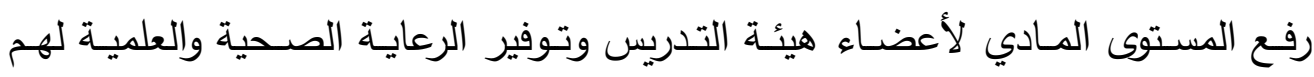
باعتبارهم العمود الفقري في العملية التعليمية. عقد مؤتمرات وندوات لتفعيل دور التعليم الجامعي لتلبية احتياجات سوق العمل. ضرورة تنظيم دورات تدريبية للطلاب والخريجين قبل وبعد التخريج تكون بمثابة تغذية التئية

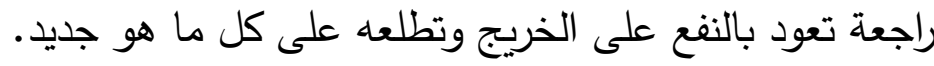

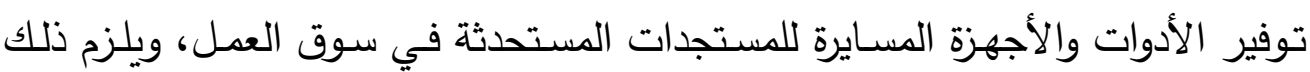
اعتماد ميزانية خاصة للتعليم الجامعي حتى يمكن تلبية احتياجات سوق العمل المختلفة. 
" العمل على وجود ممثلين من العيادة المهنية ورجال الأعمال داخل مجلس الجامعات للمشاركة في اتخاذ القرارات الخاصة بسوق العمل المصري.

تتفيذ مشروع نادي تكنولوجيا المعلومات بالجامعات وذلك من خلال التعاون مع وزارة الاتصالات والمعلومات بهدف تتمية القدرات والمهارات التقنية للطلاب والخريجين.

\section{بدوث ولراسات مستقبلية مقترحة:}

بعض مشكلات التعليم الجامعي وأثرها على تلبية احتياجات سوق العمل دراسة تحليلية. •التحديات التي تواجه التعليم الجامعي المصري في ضوء متطلبات سوق العمل. تصور مقترح لتفعيل دور التعليم العالي الفني في تلبية احتياجات سوق العمل في ضوء

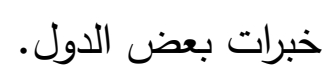

دور الجامعات في تفعيل الشراكة مـع مؤسسات سوق العمل في ضوء خبرات بعض الدول.

دراسـة تقويميـة لمخرجـات التعليم الجامعي المصـري لتلبيـة احتياجـات سوق في ضـوء خبرات بعض الدول المتقدمة. 


\section{المـــراجــع}

(Y) سـيلان جبـران العبيـدي: الموائمــة بـين مخرجـات التعلـيم الجـامعي وحاجـات المجتمـع

في الـوطن العربـي, ورقـة عمـل مقدمـة للمـؤتمر الثـاني عشـر للـوزراء المسـئولين عـن

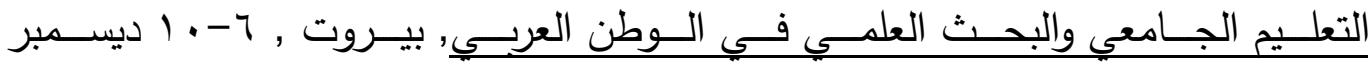
.

(T) محمد عبد الرازق إبراهيم، أحمد نصحي أنيس : "تطوير لإدارة مؤسسات التعليم الجامعي في ضـوء أسـوب حلقـات الجودة"، المـؤتمر العربي الدولي الثاني لضـمان جـودة التعليم

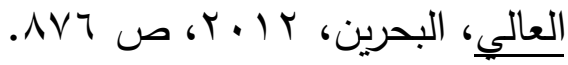

(ع) محمد عبد الظاهر الطيب : منـاهج البحث في العلوم التربوبـة والنفسية، مكتبـة الانجلو

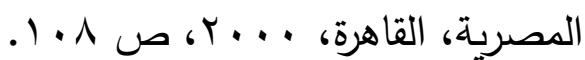

معجم مصطلحات التربية لفظا واصطلاحا، دار الوفاء، الإسكندرية، ع . . ب ص r II

مدحت القربشي : اقتصـاديات العمل، دار وائل للنشر ، جامعـة البلقاء التطبيقيـة، الأردن،

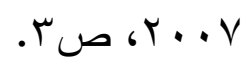

(V) رشـاد سـيد عبد الثـافي شـرف: "اسـتراتيجية مقترحسة لتطوير التعليم الجـامعي في مصـر دراسـة مسـتبلية"، رسـالة دكتوراه غيـر منشـورة، قسم أصسول التربيـة، كليـة التربيـة، جامعـة

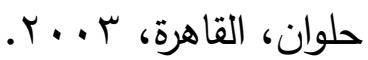

(^) عصـام عز العـرب: مسـتقبل التعليم الجـامعي المصـري في ضـوء المتغيرات المجتمعيـة المعاصرة"، رسالة ماجستير غير منشورة، كلية التربية، جامعة طنطا، 0 . . ب.

(8) Machin, Stephen \& Sandra McNally : Tertiary Education Systems and Labor Markets, Review of Tertiary Education, OECD, Paris, January 2007,

( • ( أحمد محمـود محمد الزنفلي: "التخطيط الاسـتراتيجي للتعليم الجـامعي لتلبيـة متطلبـات التتمية المستدامة"، رسالة دكتوراه غير منشورة، كلية التربية، جامعة الزقازيق، • ب. 
(1') نوال إسحاق أحمد الكندري : دراسة العلاقة بين أهمية المعرفة باحتياجات سوق العمل ومدى جودة مخرجات الخدمات التعليمية الجامعية، دراسة تطبيقية على جامعة الكويت،

(Y ( ) محمود عباس عابدين : التعليم الجامعي المصري واقعه ورؤية مستقبلية لتطويره، رسالة دكتوراه غير منشورة، الدار المصرية اللبنانية، القاهرة، V V. Y.

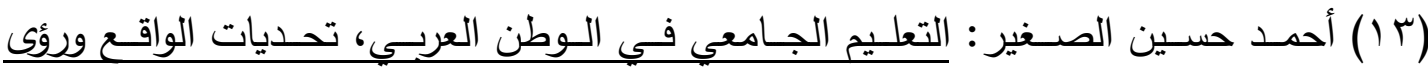

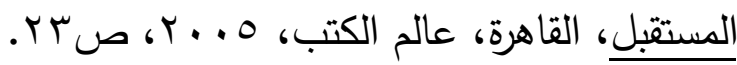

(ع ( ) البرنامج الإنمائي للأمم المتحدة ومعهد التخطيط القومي: تقربر التتمية البشربة في مصر

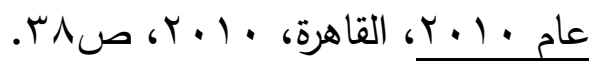

(10) المجالس القومية المتخصصة : رؤى مستتبلية لتطوير التعليم الجامعي والعالي، تقرير

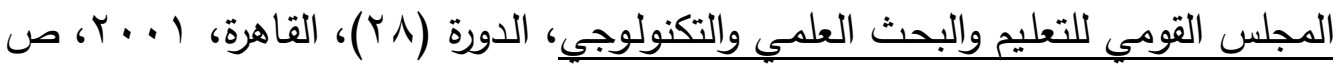

$$
\text { ص.r }
$$

(7 (1 ) حسن شحاته : ثقافة المعايير والتعليم الجامعي، بحث مقدم للمؤتمر العلمي (IV) بعنوان "منـاهج التعليم والمستويات المعياريـة"، والذي عقد بدار الضيافة بجامعة عين شمس،

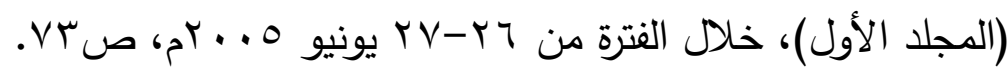

( V ( ) جمهورية مصر العربية، وزارة التعليم العالي : "قانون تنظيم الجامعات ولائحته التتفيذية

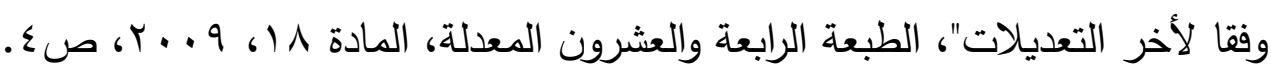
(^) (1) جمهورية مصر العربية، وزارة التعليم العالي : "قانون تنظيم الجامعات ولائحته التنفيذية

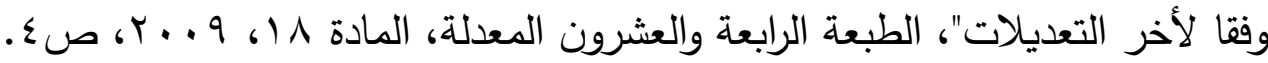
(9 (1) السعيد السعيد بدير سليمان : " تطوير إدارة التعليم الجامعى المصرى فى ضوء مدخل إدارة المعرفة : دراسـة تحليلية " مجلة الإدارة التربوية، الجمعية المصرية للتربية المقارنـة الدية

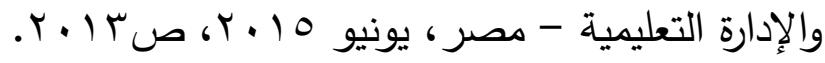


(Y. (Y) محمد على عزب : التعليم الجامعي وقضايا التمية، سلسلة التربية والمستقبل العربي،

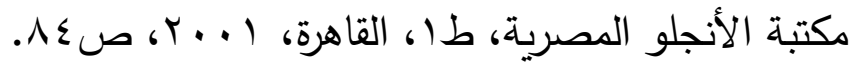

(YlY) صلاح زين الدين : تكنولوجيا المعلومات والتتمية الطريق إلى مجتمع المعرفة ومواجهة

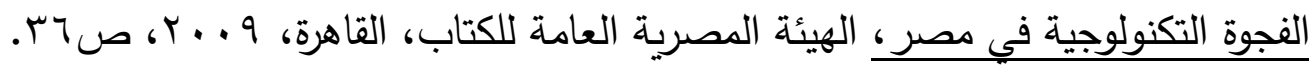
(Y أحــ حسـين الصـغير : التعليم الجـامعي في الـوطن العربـي تحديات الواقع ورؤى

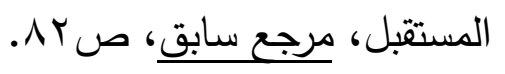

(Tr ) هاديـة محمد أبـو كليلـة : دراسـات في تخطيط التعليم واقتصـادياته، دار الوفـاء لدنيا

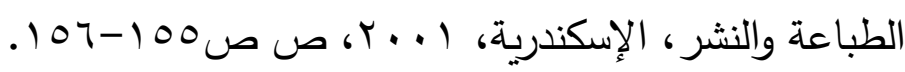

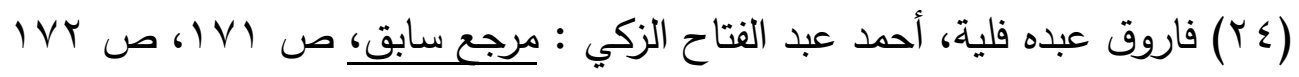

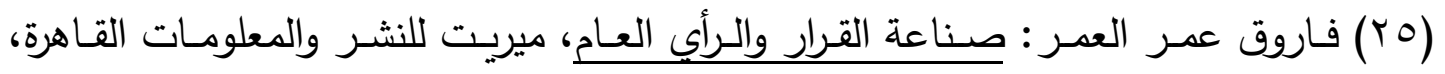

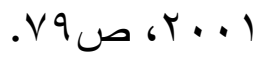

(Y (Y) محمد محمد الهادي : التعليم الإكتروني عبر شبكة الإنترنت، الدار المصرية اللبنانية،

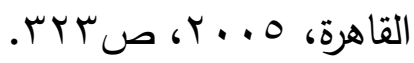

(YV) الجامعي"، المؤتمر الدولي السابع التعليم في مطلع الألفية الثالثة، جامعة القاهرة، معهد التهد

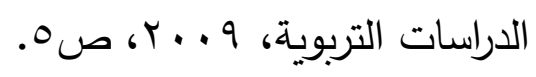

(Y^) حاتم فرغلي ضـامي : الأدوار المستقبلية للتعليم في ضوء تحولات الألفية الثالثة، الدار

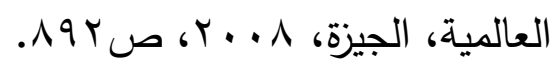
(Yq) عفاف سيد على محمد: مرجع سابق، صq بr.

(29) The World Bank: The Road Not Traveled Education Reform in the Middle East and North Africa, Washington, The World Bank, 2008, P.213. 


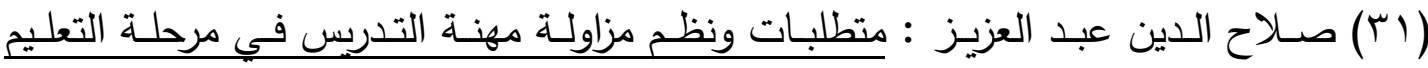

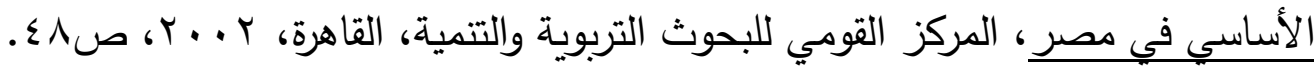
(Yr) ناهد عز الدين: "دور المؤسسة الجامعيـة: وضـع الأهداف أم تتفيذ السياسات"، المؤتمر

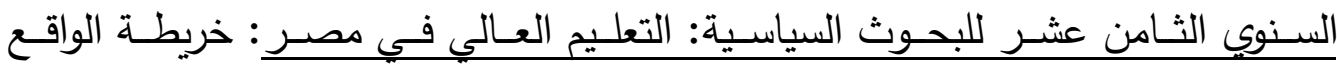
واستشراف المستقبل، المجلد الأول، مركز البحوث والدراسات السياسية، كلية الاقتصاد

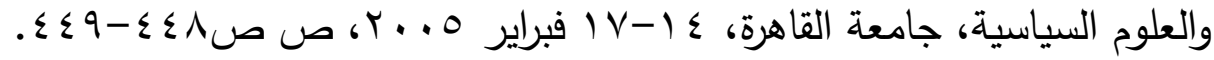
(rT) منظمة التعاون والتتمية الاقتصادية، البنك الدولي للإنشاء والتعمير : مراجعات لسياسات

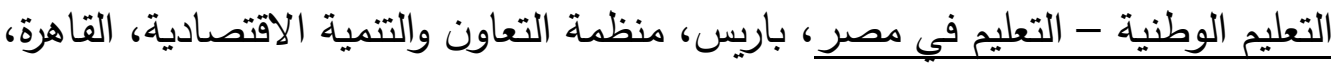

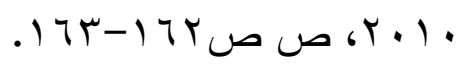

(؟) الهلالي الثربيني الهلالي: التعليم الجامعي في العالم العبي في القرن الحادي والعشرين

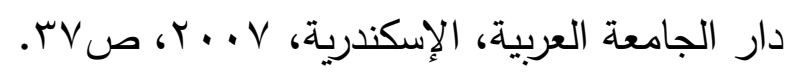

(ب0) محمد صبري حافظ محمود : بعض الرؤى لتطوير التعليم الجامعي، المؤتمر القومي

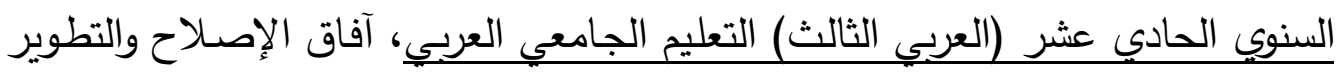

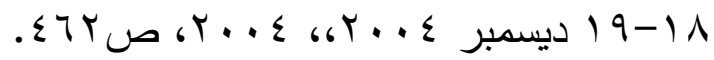

(чب) سـعيد إسـماعيل على : نحسو إسـتراتيجية لتطـوبر التعليم الجـامعي - كتـاب الأهـراد

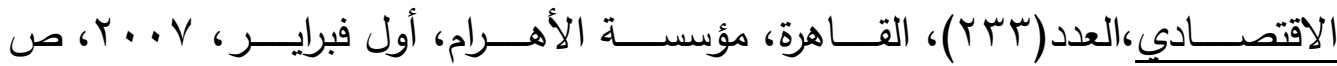

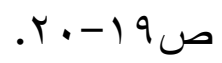

